\title{
Brazilian recommendations for the use of nonsteroidal anti-inflammatory drugs in patients with axial spondyloarthritis
}

Ricardo da Cruz Lage ${ }^{* *}$ D, Claudia Diniz Lopes Marques², Thauana Luiza Oliveira ${ }^{3}$, Gustavo Gomes Resende ${ }^{1}$, Charles Lubianca Kohem ${ }^{4}$, Carla Gonçalves Saad ${ }^{5}$, Antônio Carlos Ximenes ${ }^{6}$, Célio Roberto Gonçalves ${ }^{5}$, Washington Alves Bianchi ${ }^{7}$, Eduardo de Souza Meirelles ${ }^{5}$, Mauro Waldemar Keiserman ${ }^{8}$, Adriano Chiereghin ${ }^{9}$, Cristiano Barbosa Campanholo ${ }^{10}$, André Marun Lyrio ${ }^{11}$, Cláudia Goldenstein Schainberg ${ }^{5}$, Lenise Brandao Pieruccetti ${ }^{12}$, Michel Alexandre Yazbek ${ }^{13}$, Penelope Esther Palominos ${ }^{4}$, Rafaela Silva Guimarães Goncalves ${ }^{2}$, Rodrigo Luppino Assad ${ }^{14}$, Rubens Bonfiglioli1 ${ }^{11}$ Sônia Maria Alvarenga Anti Loduca Lima ${ }^{15}$, Sueli Carneiro ${ }^{16}$, Valderílio Feijó Azevedo ${ }^{17}$, Cleandro Pires Albuquerque ${ }^{18}$, Wanderley Marques Bernardo ${ }^{5}$, Percival Degrava Sampaio-Barros ${ }^{5}$ and Marcelo de Medeiros Pinheiro ${ }^{3}$

\begin{abstract}
Spondyloarthritis (SpA) is a group of chronic inflammatory systemic diseases characterized by axial and/or peripheral joints inflammation, as well as extra-articular manifestations. Over some decades, nonsteroidal anti-inflammatory drugs (NSAIDs) have been the basis for the pharmacological treatment of patients with axial spondyloarthritis (axSpA). However, the emergence of the immunobiologic agents brought up the discussion about the role of NSAIDs in the management of these patients. The objective of this guideline is to provide recommendations for the use of NSAIDs for the treatment of axSpA. A panel of experts from the Brazilian Society of Rheumatology conducted a systematic review and meta-analysis of randomized clinical trials for 15 predefined questions. The Grading of Recommendations, Assessment, Development and Evaluation methodology to assess the quality of evidence and formulate recommendations were used, and at least 70\% agreement of the voting panel was needed. Fourteen recommendations for the use of NSAIDs in the treatment of patients with axSpA were elaborated. The purpose of these recommendations is to support clinicians' decision making, without taking out his/her autonomy when prescribing for an individual patient.
\end{abstract}

Keywords: Spondyloarthritis, Ankylosing spondylitis, Nonsteroidal anti-inflammatory drugs, Systematic review, Meta-analysis, Guidelines

\footnotetext{
* Correspondence: ricolage@gmail.com

${ }^{1}$ Universidade Federal de Minas Gerais (UFMG), Alameda Álvaro Celso 175,

Ambulatório Bias Fortes, $2^{\circ}$ andar, Belo Horizonte, MG 30150-260, Brazil

Full list of author information is available at the end of the article
}

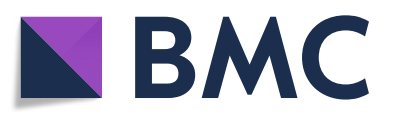

(c) The Author(s). 2021 Open Access This article is licensed under a Creative Commons Attribution 4.0 International License, which permits use, sharing, adaptation, distribution and reproduction in any medium or format, as long as you give

appropriate credit to the original author(s) and the source, provide a link to the Creative Commons licence, and indicate if changes were made. The images or other third party material in this article are included in the article's Creative Commons licence, unless indicated otherwise in a credit line to the material. If material is not included in the article's Creative Commons licence and your intended use is not permitted by statutory regulation or exceeds the permitted use, you will need to obtain permission directly from the copyright holder. To view a copy of this licence, visit http://creativecommons.org/licenses/by/4.0/. 


\section{Background}

Spondyloarthritis (SpA) is a set of diseases that cause inflammation of the spine and peripheral joints and may have extra-articular manifestations, such as anterior uveitis, psoriasis, and inflammatory bowel disease. The main manifestation of SpA is the involvement of the entheses, attachment sites of the tendons, capsules, and ligaments to the bones, especially Achilles' tendon and plantar fascia. Frequently, axSpA patients have a genetic predisposition linked to human leukocyte antigen (HLA)-B27 and are usually seronegative for rheumatoid factor. The set of diseases consists of ankylosing spondylitis (AS), psoriatic arthritis, reactive arthritis, enteropathic arthritis and undifferentiated spondyloarthritis. Axial spondyloarthritis $(\operatorname{axSpA})$ is defined as all cases involving the spine and/or sacroiliac joints, and peripheral spondyloarthritis is defined as cases involving only peripheral joints and/ or peripheral entheses. When the same patient has both types of conditions, he/she should be classified by the predominant segment (predominantly axial involvement or predominantly peripheral involvement) [1-4].

AxSpA comprises the so-called radiographic form or AS, which includes patients who present sacroiliitis on simple radiography according to the modified New York criteria, and non-radiographic axial spondyloarthritis (nr-axSpA), which is diagnosed according to the presence of HLA-B27 (clinical arm) or positive sacroiliac MRI (imaging arm), according to the 2009 Assessment in Ankylosing Spondylitis (ASAS) classification criteria [1-4]. Although there is currently no consensus, the prevailing opinion is that axSpA is a single disease in which $20-30 \%$ of patients with $\mathrm{nr}-\mathrm{axSpA}$ can develop radiographic changes over time (5 to 10 years) [5]. In fact, radiographic sacroiliitis artificially splits the axSpA spectrum into two groups, and it is unlikely that its presence alone is critical to the outcome [6]. Thus, the present recommendations will address axSpA as a single entity and combine all relevant data, since most of the available studies included patients with the radiographic form.

Over some decades, nonsteroidal anti-inflammatory drugs (NSAIDs) have been the basis for the pharmacological treatment of axSpA. However, with the emergence of biological agents which have brought great benefit to patients with axSpA, the discussion about the role of NSAIDs, as well as its cost/effectiveness and safety has gained attention.

Recently, the Brazilian Society of Rheumatology has published evidence based recommendations for the diagnosis and management of axSpA [7]. Our main goal in the present guideline was to specifically evaluate the role of NSAIDs for treating axSpA patients through a systematic review with meta-analysis and critical analysis of the published scientific data.

\section{Methodology \\ Study design}

This guideline was conducted in two phases. In the first phase, a systematic review and meta-analysis of randomized clinical trials (RCTs) were performed. In the second phase, an expert panel answered predefined questions and developed the recommendations.

\section{Systematic review and meta-analysis Inclusion criteria}

We included RCTs, systematic reviews, and metaanalyses that have evaluated the efficacy and safety of NSAIDs, as monotherapy or in combination with TNFi or IL17i, in patients older than 18 years of age with $\operatorname{axSpA}$.

\section{Exclusion criteria}

Non-randomized comparative studies, non-comparative studies, studies published only as conference abstracts, narrative reviews, animal studies, in vitro studies were excluded. Additionally, studies that evaluated the efficacy and safety of NSAIDs in populations with peripheral spondyloarthritis (psoriatic arthritis, reactive arthritis, inflammatory bowel disease) or rheumatoid arthritis were excluded.

\section{Definition of therapeutic intervention}

Studies that evaluated intervention with NSAIDs as a class (total or selective and nonselective COX-2 inhibitors), as well as studies that evaluated NSAID-specific molecules alone or in combination with TNFi or IL17i were considered.

\section{Definition of controls}

The included studies that evaluated the efficacy and safety of NSAIDs were compared to placebo or active treatment.

\section{Efficacy outcomes}

The outcomes used are shown in the Suplemmentary Material and included parameters of disease activity, functionality, and progression of axial and peripheral damage. Not all outcomes were reported in all comparisons, although most outcomes were included in each of them.

\section{Safety outcomes}

Any adverse events were considered, regardless of severity, causal relationship, and resolution, including renal, cardiovascular, gastrointestinal, neurological, dermatologic, hematologic and hepatic events. 


\section{Data sources}

The search was conducted in the electronic databases MEDLINE (via PubMed), EMBASE, and the Cochrane Library. In addition, ongoing studies were searched in the Clinical Trials.gov and World Health Organization (WHO) trial registration databases. We searched for other potential studies not retrieved by the search strategies by checking the reference list of each eligible study, as well as in the electronic databases Health Technology Assessment (HTA), Database of Abstracts of Reviews of Effects (DARE), and National Institute for Health and Care Excellence (NICE), in addition to the guidelines of specialty societies.

Search strategies, eligibility assessment, data extraction and risk of bias assessment are shown in the Supplementary Material.

\section{References eligible for meta-analyses}

Through the search strategies reported above, 1915 references were retrieved (369 in Medline, 1532 in EMBASE, and 14 in the Cochrane Library) that were published from January 1, 2014 until May 31, 2018 (update date since the review by Kroon et al., 2015) [8]. After removing duplicates, 1698 references were evaluated by reading titles and abstracts, of which 1666 were excluded. Thus, 32 references were evaluated by reading their complete texts. At this stage, 29 references were excluded: 18 according to the type of study [9-26] (noncomparative studies; observational, single-arm studies; systematic reviews without meta-analysis or with overlapping studies; language other than Portuguese, English, or Spanish; and abstracts); eight according to the type of intervention [27-34] (drugs not registered in the country and anti-inflammatory agents other than NSAIDs); two according to the type of outcome $[35,36]$ (indirect/incomplete analyses, ineligible outcome); and one according to the type of population [37] (not AS and not spondyloarthritis). Thus, three RCTs [38-40] were considered eligible. In addition, through the search of the reference list of the studies evaluated, one RCT was manually included [41]. Therefore, four new eligible references were added to those previously analyzed by Kroon et al. (2015) [8].

Also, additional searches were performed into ClinicalTrials.gov and WHO International Clinical Trials Registry Platform databases. At ClinicalTrials.gov, 19 records were found, of which 17 reported no results. The two trials with available data, presented results before the review of Kroon et al. [8], they were not eligible. In the WHO International Clinical Trials Registry Platform, 18 reports of 15 RCT registrations were found. However, as they did not have available results, they were not included in this meta-analysis (Fig. 1).

\section{Meta-analyses}

Meta-analyses were performed for outcomes commonly reported by at least two studies. Their results are presented in the form of forest plots and are described in the text. Outcomes reported by only one study were also presented in graphical form (Supplementary Material).

\section{Measures of association}

For dichotomous variables, the measure of association used was relative risk (RR) with its respective 95\% confidence interval (CI). For continuous variables, the measure of association used was the mean difference (MD) with its respective $95 \%$ CI. If the studies evaluated the same outcome, but using different scales, the measure of association used was the standardized mean difference (SMD) with its respective 95\% CI.

\section{Statistical methods}

For the outcomes of dichotomous variables, the method used for the meta-analysis was the Mantel-Haenszel method. For the outcomes of continuous variables, the method used for the meta-analysis was the inversevariance weighting.

\section{Analytical model}

The random-effects model was used when the statistical heterogeneity was significant by the Cochrane chisquared test $(p<0.1)$. However, if the statistical heterogeneity was not significant but was moderate or high $\left(\mathrm{I}^{2} \geq 30 \%\right)$, the results are presented according to the random-effects model. In cases of mild statistical heterogeneity $\left(\mathrm{I}^{2}<30 \%\right)$ or lack of statistical heterogeneity, the fixed-effects model was preferably used to add greater weight to the estimates from studies with larger sample sizes.

\section{Heterogeneity}

In cases of statistical heterogeneity, such heterogeneity was explored based on 2 strategies: the clinicaldemographic differences of the participants among studies or study design differences and subgroup analyses. Some subgroup analyses were defined in advance because they were of clinical interest. These subgroup divisions were present or absent HLA-B27, normal or elevated C-reactive protein (CRP), normal or elevated erythrocyte sedimentation rate (ESR), present or absent syndesmophyte, and male or female sex.

The description of each included RCT, the risk of bias analyses, the evaluation of the quality of the evidence according to Grading of Recommendations Assessment, Development and Evaluation (GRADE) [42, 43] and the meta-analyses with all the forest plots are available in the Supplementary Material. 


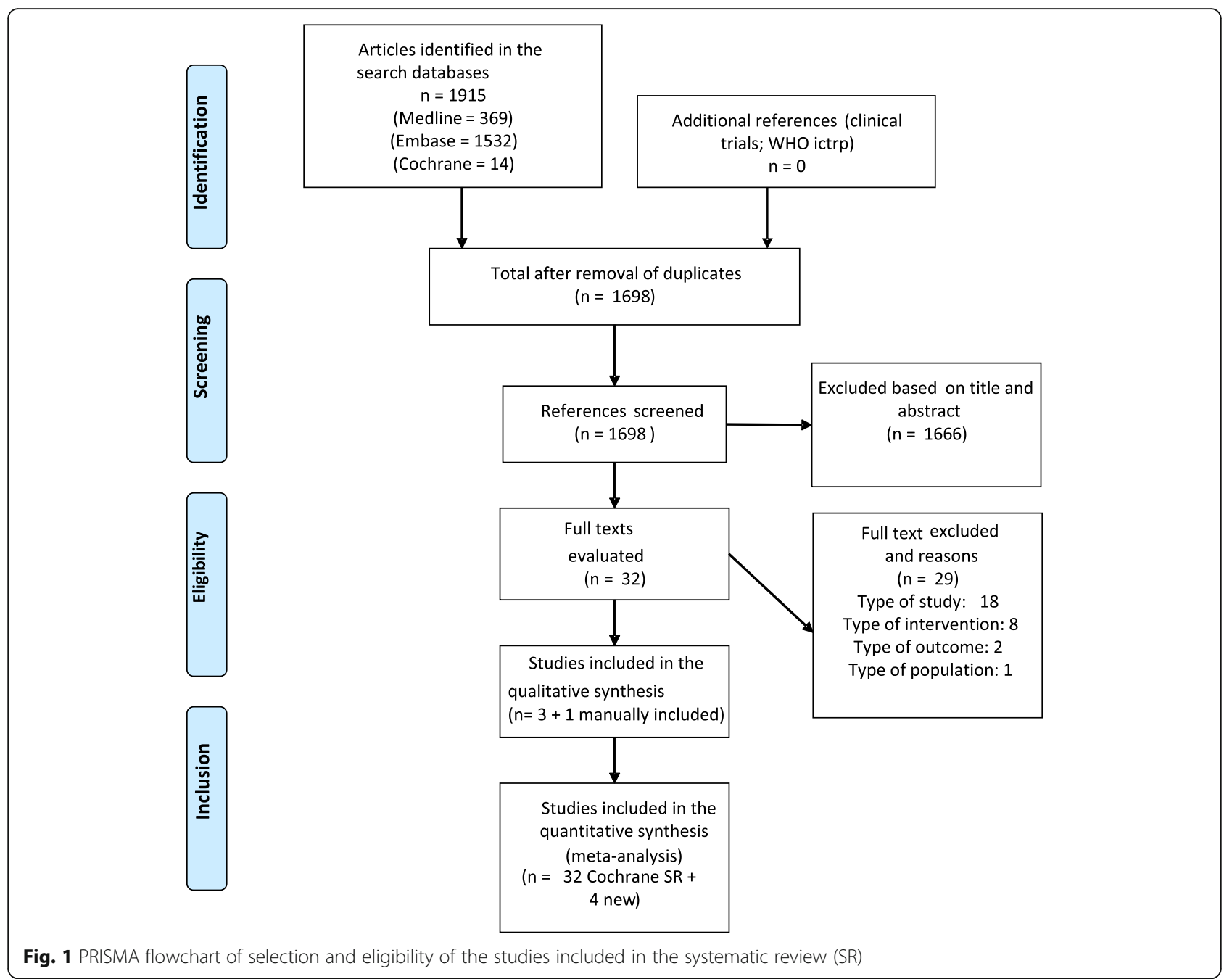

\section{Development of recommendations}

A panel of 28 rheumatologists with expertise in SpA elaborated 15 questions divided into 6 sections: efficacy and effect size, window of opportunity and treatment strategy, continuous or on demand use, radiographic progression, comparison of different NSAIDs, safety and adverse reactions. Regarding not answered questions according to the current evidence, the data from individual RCTs were reported. If necessary, a manual search for available evidences, including observational studies, was performed to support the recommendations. There was a hierarchic and standardized sequence to report available evidence: meta-analysis, individual RCTs, and finally observational studies. Observational studies were always reported as very low-quality evidence and supported conditional recommendations.

These recommendations followed the GRADE methodology. Strength of recommendation was determined by the balance between desirable and undesirable consequences of alternative management strategies, quality of evidence, variability in values and preferences, and resource use. Strong recommendations mean that most informed patients would choose the recommended management and that clinicians can structure their interactions with patients accordingly. Weak or conditional recommendations mean that patients' choices will vary according to their values and preferences, and clinicians must ensure that patients' care is in keeping with their values and preferences. The quality of evidence was assessed using GRADE for predefined key outcomes (Supplementary Material) $[42,43]$.

The degree of expert agreement (inter-rater reliability) was determined by the Delphi method through an online anonymous survey, and a minimum $70 \%$ agreement was needed for each recommendation.

Table 1 summarizes the Brazilian recommendations for the use of NSAIDs in patients with axSpA. 
Table 1 Brazilian recommendations for the use of nonsteroidal anti-inflammatory drugs in patients with axial spondyloarthritis

Recommendation 1. In patients with active axSpA, we strongly recommend treatment with NSAIDs over no treatment, because they are effective for mitigating disease activity measures and improving functional status.

Recommendation 2. In patients with persistent active axSpA, we strongly recommend long-term over short-term use of NSAIDs, because they exhibit sustained symptomatic efficacy. We conditionally recommend that disease activity and adverse events should be regularly monitored, evaluating long-term risks versus benefits.

Recommendation 3. In patients with active axSpA, we conditionally recommend treatment with NSAIDs over no treatment for alleviate symptoms of peripheral arthritis and enthesitis, since few data have shown moderate efficacy in these clinical manifestations.

\section{WINDOW OF OPPORTUNITY AND TREATMENT STRATEGY}

Recommendation 4. In patients with active axSpA, we strongly recommend NSAIDs as the first-line treatment over an immunobiologic agent, considering its low cost and satisfactory efficacy. The benefit of starting an immunobiologic agent in NSAIDs-naiive patients, even in those with poor prognostic criteria, is not proven.

Recommendation 5. In patients with active axSpA, we strongly recommend to immediately start a NSAID after the very low

low

low

diagnosis because early treatment may increase the response rate.

Recommendation 6. In patients with active axSpA, we strongly recommend to initiate NSAIDs at full dosage over Iow dosage, because they exhibit a tendency for greater efficacy in achieving ASAS 20, reduction of morning stiffness, BASDAI, pain, patient global assessment of disease activity, and BASFI. We conditionally recommend that the full dosages of NSAIDs should be maintained, with adequate monitoring, until good disease control is achieved.

Recommendation 7. In patients with active axSpA, in the absence of a response to the first NSAID at 4 weeks, we conditionally recommend switching to a second traditional NSAID or iCOX2. If the therapeutic target is not reached with the use of NSAIDs for 12 weeks, we strongly recommend to start an immunobiologic agent.

\section{CONTINUOUS OR ON-DEMAND USE}

Recommendation 8. In patients with active axSpA, we conditionally recommend to start continuous over ondemand NSAIDs until symptoms relief is achieved. After clinical improvement or the clinical target (low disease activity or remission) has been achieved, the full dosage can be reduced or switched to on-demand strategy. Before prescribing continuous NSAIDs, it is important to take into account: the patient's opinion, comorbidities and risk factors.

\section{RADIOGRAPHIC PROGRESSION}

Recommendation 9. Regarding radiographic progression, in patients with active axSpA, we conditionally recommend continuous over on demand use of NSAIDs. Considering controversial results among the studies, we conditionally recommend switching to on demand strategy in inactive disease. We conditionally recommend against switching NSAIDs to immunobiological therapy when there is radiographic progression without evidence of disease activity, because the risk/benefit ratio of starting an immunobiologic agent in this scenario is not clear.

\section{COMPARISON AMONG NSAIDs}

Recommendation 10. In patients with active axSpA, we conditionally recommend that the choice of specific NSAl D should be based on patient's profile (age, prior toxicity, comorbidities) and on shared decision making. To date, there is no consistent evidence of efficacy and safety differences among the NSAIDs (non-selective or iCOX2) in axSpA.

\section{SAFETY AND ADVERSE REACTIONS}

Recommendation 11. Regarding safety, in patients with active axSpA, we strongly recommend treatment with NSAIDs over no treatment, because the available evidence showed an overall good safety profile of these drugs in axSpA.

We conditionally recommend that NSAIDS should be used with caution in individuals with risk factors (age $>65$ years, diabetes mellitus, use of aspirin, corticosteroids and other platelet antiaggregants, renal or liver diseases). The risks and benefits of starting them should be shared and individualized according to the patient's risk profile.

\section{Gastrointestinal}

Recommendation 12. In patients with active axSpA, we conditionally recommend to avoid NSAIDs (non-selective or iCOX2) and to start an immunobiologic agent in those with current or previous peptic ulcer or gastrointestinal bleeding.

We conditionally recommend the use of an iCOX2 agent over a traditional NSAID in patients with gastrointestinal risk factors.

We strongly recommend the use of concomitant gastroprotective drugs in symptomatic or high-risk patients.

\section{Cardiovascular}

Recommendation 13. In patients with active axSpA, we conditionally recommend to avoid NSAID therapy and to start an immunobiologic agent in those with cardiovascular risk factors, mainly in those with previous acute myocardial infarction or stroke, especially if recent (past 12 months). low 
Table 1 Brazilian recommendations for the use of nonsteroidal anti-inflammatory drugs in patients with axial spondyloarthritis (Continued)

\begin{tabular}{|c|c|c|}
\hline Recommendations & QoE & DoA \\
\hline \multicolumn{3}{|l|}{ Renal } \\
\hline $\begin{array}{l}\text { Recommendation 14. In patients with active axSpA, we conditionally recommend to avoid NSAIDs and to start an } \\
\text { immunobiologic agent in thoses with increased risk of renal adverse events. The decision should be individualized } \\
\text { and risk/benefits shared with the patient. } \\
\text { We strongly recommend caution and regular monitoring of renal function, especially in high-risk individuals (elderly, } \\
\text { hypertension, diabetes, kidney dysfunction). }\end{array}$ & $\begin{array}{l}\text { very low (observa-tional } \\
\text { studies) }\end{array}$ & 9.4 \\
\hline
\end{tabular}

\section{Recommendations}

\section{Efficacy and effect size}

Are NSAIDs effective for treating patients with axSpA?

Five RCTs evaluated the efficacy of conventional NSAI Ds, and three evaluated cyclooxygenase 2-selective inhibitors (iCOX2) compared to placebo. A total of 2002 patients with active AS, with a mean age between 40 and 45 years and a predominance of men $(60 \%)$, were included in these studies and were followed up for 2 to 52 weeks [44-48].

There was a superiority of traditional NSAIDs over placebo for the following outcomes: pain by VAS (0$100 \mathrm{~mm}$ ), patient global assessment (PGA) of disease activity by VAS $(0-100 \mathrm{~mm})$, duration of morning stiffness in minutes, C-reactive protein concentration, at least $20 \%$ improvement according to the ASAS group response criteria (ASAS 20), at least 50\% improvement in pain, and the Bath Ankylosing Spondylitis Function Index (BASFI) (Table 2).

Regarding iCOX2, the meta-analyses showed superiority over placebo in the following outcomes: pain VAS, PGA, ASAS 20, and BASFI (Table 2). Individual studies showed superiority of iCOX2 over placebo in the Bath Ankylosing Spondylitis Disease Activity Index (BASDAI) [-2.2 (-2.74 to -1.66$)]$ [48], at least $50 \%$ improvement in pain [iCOX2: $47.5 \%$ vs placebo: $20 \%$, RR: 2.41 (1.45 to 4.00)] [45], and ASAS partial remission [iCOX2: $15 \%$ vs placebo: 3\%, RR: 4.65 (1.39 to 15.55)] [48]. Fig. 2 shows the subgroup analysis for pain VAS by comparing traditional NSAIDs, iCOX2, or both versus placebo.

\section{Recommendation 1}

In patients with active axSpA, we strongly recommend treatment with NSAIDs over no treatment, because they are effective for mitigating disease activity measures and improving functional status. Quality of evidence: low; Degree of agreement: 9.8

\section{Do NSAIDS have sustained symptomatic efficacy in axSpA?} Most RCTs that evaluated the efficacy of NSAIDs, compared to both placebo and other NSAIDs, had a short duration (8 to 12 weeks) [13, 29, 31, 38, 40, 44, 47, 49-53]. In two long-term RCTs involving patients with AS, the sustained efficacy of NSAIDs was shown in 12 months. Van der Heijde et al. found an ASAS20 response of $52.5 \%$ with naproxen and $65 \%$ with etoricoxib compared to $20 \%$ in placebo group. The 1-year maintenance rate was $90 \%$ with etoricoxib and $79 \%$ with naproxen [48]. In another RCT, Dougados et al. evaluated the efficacy of NSAIDs in 473 patients with short- and long-term AS. At 6 weeks, 43, 50, and 47\% of patients who received $20 \mathrm{mg}$ of piroxicam, $15 \mathrm{mg}$ of meloxicam, or $22.5 \mathrm{mg}$ of meloxicam, respectively, had $\geq 50 \%$ improvement in PGA, compared to $21 \%$ for the placebo,

Table 2 Efficacy of traditional NSAIDs or iCOX2 vs. placebo in patients with axial spondyloarthritis: meta-analyses of randomized clinical trials

\begin{tabular}{|c|c|c|}
\hline & $\begin{array}{l}\text { TRADITIONAL NSAIDs } \\
n=1289\end{array}$ & $\begin{array}{l}\mathrm{iCOX2} \\
n=669\end{array}$ \\
\hline PAIN VAS $(95 \% \mathrm{Cl})$ & $-16.75(-20.28$ to -13.07$)$ & $-21.68(-35.94$ to -7.42$)$ \\
\hline PGA & $-17.75(-24.39$ to -11.10$)$ & $-20.82(-39.88$ to -11.75$)$ \\
\hline ASAS20 & $\begin{array}{l}60 \% \text { vs. } 23 \%(\mathrm{PbO}) \\
\mathrm{RR}=2.49(1.94 \text { to } 3.19)\end{array}$ & $\begin{array}{l}57 \% \text { vs. } 20 \% \text { (PbO) } \\
\text { RR=2.51 ( } 1.66 \text { to } 3.79)\end{array}$ \\
\hline BASFI & $-9(-13$ to -5$)$ & $-13.4(-17.3$ to -5$)$ \\
\hline MS - SMD & $-0.4(-0.58$ to -0.22$)$ & NA \\
\hline CRP mg/L & $-3.37(-6.11$ to -0.62$)$ & NA \\
\hline PAIN50\% & $\begin{array}{l}48 \% \text { vs } 21 \% \\
2.25 \text { (1.75 to } 2.89)\end{array}$ & NA \\
\hline
\end{tabular}

NSAIDs nonsteroidal anti-inflammatory drugs, iCOX2 COX-2-selective inhibitors, PAIN VAS pain by visual analog scale 0-100 mm, PGA Patient Global Assessment 0$100 \mathrm{~mm}, B A S F I$ Bath Ankylosing Spondylitis Function Index 0-100 mm, MS-SMD standardized mean difference in the duration of morning stiffness, CRP C-reactive protein, PAIN50\% $\geq 50 \%$ improvement in pain, $R R$ relative risk, $P b O$ placebo, N/A meta-analysis not feasible 


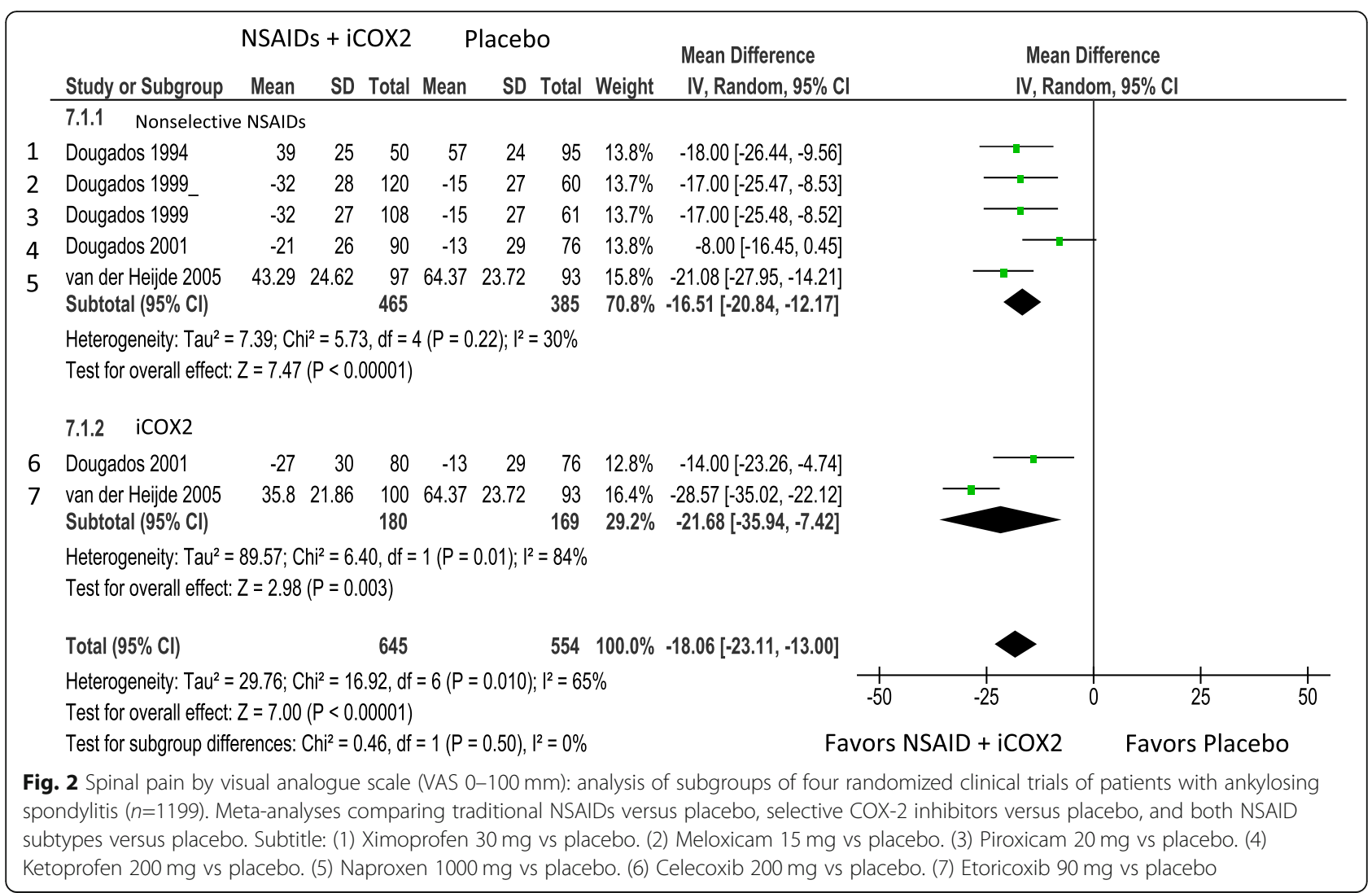

with sustained response at 12 months. The discontinuation rate due to lack/ loss of efficacy was between 10 and $20 \%$. Only $16 \%$ of the responders at 6 weeks had a 1 -year loss of response [46].

In a German population-based cohort, almost $80 \%$ of 1080 patients with AS were on NSAIDs, of whom $71 \%$ had been taking it for more than 4 years. The NSAIDs were effective for complete or partial resolution (>50\%) of pain in 19.1 and $61.2 \%$ of patients, respectively [54]. In a Swedish cohort, 21, 108 patients with AS were analyzed for 3 years. Approximately $80 \%$ of patients used iCOX2, and $63.8 \%$ used nonselective NSAIDs for more than $50 \%$ of the follow-up time, with a good initial response rate as well as a good response rate over time [17]. In the Netherlands, Carbo et al. followed up 393 patients with AS who were anti-TNF naïve, of whom 254 were prescribed some TNF inhibitors (BASDAI $=6.1$ and ASDAS=3.8), while 139 were kept under conventional treatment (BASDAI $=3.9$ and ASDAS $=2.4 ; 74 \%$ with NSAIDs). After 12 months of follow-up, both groups had similar activity scores $(\mathrm{BASDAI}=3.4$ and $\mathrm{ASDAS}=2.2$ vs. $\mathrm{BASDAI}=3.7$ and $\mathrm{ASDAS}=2.3$, respectively). Among patients who received conventional treatment, $82 \%$ maintained a sustained response with NSAIDs after 52 weeks [55]. Despite being observational studies whose primary objective was not to evaluate the response to treatment, the high rate of drug retention observed over time suggested a sustained efficacy of NSAIDs.

\section{Recommendation 2}

In patients with persistent active axSpA, we strongly recommend longterm over short-term use of NSAIDs, because they exhibit sustained symptomatic efficacy. We conditionally recommend that disease activity and adverse events should be regularly monitored, evaluating long-term risks versus benefits.

Quality of evidence: low; Degree of agreement: 9.3

\section{Are NSAIDs effective for treating the peripheral manifestations of axSpA?}

Four of the five RCTs of NSAIDs versus placebo did not evaluate the efficacy of these drugs on peripheral arthritis or enthesitis in axSpA. One RCT compared the effect of ximoprofen on peripheral arthritis at several doses with placebo as secondary outcome, and there was a significant improvement in peripheral arthritis with a moderate effect size (standardized mean difference, $\mathrm{SMD}=0.62$ [95\%CI: 0.26 to 0.97$])[47,56]$. From the three trials that assessed iCOX2 versus placebo, two of them excluded patients with peripheral manifestations. A post-hoc analysis of a study of etoricoxib and naproxen versus placebo in axSpA suggested NSAIDs were effective for treating peripheral arthritis, as assessed by question 3 of BASDAI, with an improvement on the VAS $0-100 \mathrm{~mm}$ of $-16.4(-20.3$ to -12 . 6) compared to 0.9 ( -5.9 to 7.6$)$ for placebo, as well as in enthesitis (question 4 of BASDAI), with a shift of $-21.3(-25.2$ to - 
17.5) with NSAID versus -6.5 ( -13.3 to 0.4$)$ with placebo in patients with concomitant peripheral arthritis, and of $27.6(-30.8$ to -24.5$)$ versus $-7.3(-12.9$ to -1.8$)$ in those without concomitant peripheral arthritis [48, 50].

The effect of NSAIDs on enthesitis was not specifically evaluated in RCTs of patients with axSpA. The current recommendations suggest that they are effective in a subsample of patients, but that conclusion was extrapolated from studies on psoriatic arthritis or based on expert opinions $[57,58]$.

\section{Recommendation 3}

In patients with active axSpA, we conditionally recommend treatment with NSAIDs over no treatment to alleviate symptoms of peripheral arthritis and enthesitis, since few data have shown moderate efficacy in these clinical manifestations. Quality of evidence: very low; Degree of agreement: $\mathbf{8 . 8}$

\section{Window of opportunity and treatment strategy} Should NSAIDs be considered first-line treatment in axSpA? In the INFAST study, 158 patients with axSpA were randomized to receive infliximab + naproxen or placebo + naproxen for 28 weeks. The interesting aspect of this study was that the patients were not refractory to NSAI Ds, as in other immunobiologic RCTs (they were NSAID naïve or used low dose of NSAIDs). At week $28,62 \%$ of the Infliximab + naproxen group had ASAS partial remission versus $35 \%$ of the placebo + naproxen group [59]. Later, infliximab was discontinued, and patients who achieved remission were monitored until week 52 under continuous naproxen use or no treatment. A similar percentage maintained remission in both the group using naproxen $(47.5 \%)$ and the group without any treatment (40\%) and independent of the initial therapeutic regimen, despite small sample for the latter analysis. The response rate was higher with anti-TNF, but NSAIDs (with placebo) led to remission in more than $1 / 3$ of the cases [60].

In an open-label follow-up study, 39 of the 40 patients with very early axSpA from the RCT conducted by Barkham et al [61] (who had received infliximab or placebo for 16 weeks) were monitored for 5 years. There was no difference in current disease activity or radiographic progression by mSASSS among participants receiving infliximab or placebo in the randomized phase. However, approximately $60 \%$ (7/ 12) of patients who initially received infliximab still needed an anti-TNF after 5 years, while $100 \%(13 / 13)$ of those who received placebo remained on anti-TNF treatment [62].

There are not available data to define whether NSAIDs should remain the first-line treatment in patients with poor prognostic criteria (smokers, with elevated CRP and syndesmophytes on baseline) or whether immunobiologics should be the first choice in these cases. Indeed, the long-term benefit of initiating an immunobiologic agent as first line treatment was not proven, as the data suggesting this benefit originated from a small sample size [62]. In addition, early starting of the NSAID led to a highly significant ASAS partial remission rate (35\%) [59].

Considering the low cost, long term experience, and satisfactory response in early disease showed in the INFAST trial [59], the expert panel stated that NSAIDs should still be the first-line treatment in axSpA.

\section{Recommendation 4}

In patients with active axSpA, we strongly recommend NSAIDs as the first-line treatment over an immunobiologic agent, considering its low cost and satisfactory efficacy. To date, the benefit of starting an immunobiologic agent in NSAIDs-naïve patients, even in those with poor prognostic criteria, is not proven. Quality of evidence: low; Degree of agreement: $\mathbf{8 . 6}$

\section{Should NSAIDs be started immediately after the diagnosis of axSpA?}

Several studies suggest that the response rates are higher with an earlier onset of treatment [39, 63-65]. In the INFAST study [59], approximately $35 \%$ of patients with very early $(<2$ years of disease on average) axSpA (AS + nr-axSpA) achieved ASAS partial remission with naproxen versus $9 \%$ with placebo (only $15 \%$ of patients with AS, with longer disease duration, had achieved this target with etoricoxib in the study by van der Heijde et al) [48]. Barkham et al. achieved 56\% ASAS partial remission with infliximab in patients with early axSpA (average of 1 year and 3 months of symptom duration) compared to $22 \%$ in the pivotal study of infliximab [61]. Other RCTs found a 70 to $75 \%$ ASAS40 response rate after TNF inhibitors in patients with axSpA and disease duration below 3 years, compared to around $40-45 \%$ of ASAS40 response rate in those with established AS [59, $66,67]$. Haroon et al. reinforced the importance of early treatment by demonstrating that the delay in the onset of anti-TNF treatment increases the rate of radiographic progression [68]. These results reinforce the idea of a "window of opportunity" during the treatment of axSpA and the importance of effective early onset treatment.

Despite the few available data, the panelists considered important to immediately start an NSAID as soon as the diagnosis of axSpA is confirmed.

\footnotetext{
Recommendation 5

In patients with active axSpA, we strongly recommend to immediately start an NSAID after the diagnosis, because early treatment may increase the response rate. Quality of evidence: very low; Degree of agreement: 8.8
}

When NSAIDs are prescribed for the treatment of patients with axSpA, should they be used in full dosages or at the lowest possible dosage for symptomatic control?

Six RCTs compared full-dosage versus low-dosage of NSAI Ds in almost 2000 patients with active axial SpA. In two of 
them the mean disease duration was long (10 to 13 years) $[46,47]$. The comparisons were: 1 ) celecoxib $200 \mathrm{mg}$ x celecoxib $400 \mathrm{mg}[44,49]$; 2) ximoprofen $5 \mathrm{mg} \mathrm{x}$ ximoprofen 30 mg [47]; 3) meloxicam $15 \mathrm{mg}$ x meloxicam $22.5 \mathrm{mg}$ [46]; 4) etoricoxib $90 \mathrm{mg} \mathrm{x}$ etoricoxib $120 \mathrm{mg}$ [48]; and 5) etoricoxib $60 \mathrm{mg} x$ etoricoxib $90 \mathrm{mg}$ [41]. The meta-analyses showed a slight superiority of the higher dosages of NSAIDs in reducing the duration of morning stiffness [SMD: 0.14 (0.02; 0.27)] and the proportion of patients who achieved ASAS 20 [RR: $0.87(0.77 ; 0.99)]$, at the limit of statistical significance. However, there was uncertain risk of bias in four studies [44, 46, 47, 49] and high risk in one study [41]. Regarding the BASDAI and BASFI, the meta-analyses did not demonstrate a significant difference between full- and low-dosage NSAI Ds, but the results of the individual studies were consistent in favoring higher dosage. Regarding pain outcomes, including pain VAS and 50\% improvement, CRP serum levels and PGA, the data were inconsistent, sometimes favoring high doses and other times favoring lower doses of NSAIDs. ASAS partial remission [48] and BASMI [49] were reported in only one RCT each, with no difference between doses. Also, the results of the RCTs cited above should be interpreted with caution, as the $120 \mathrm{mg}$ dose of etoricoxib and $22.5 \mathrm{mg}$ of meloxicam are not currently in use.

Regarding safety, the meta-analyses showed no differences among NSAIDs dosages on the occurrence of any adverse event, serious adverse event, or adverse events per specific system (cardiovascular, gastrointestinal, neurological, respiratory, or dermatologic). There was also no difference in the proportion of patients who discontinued treatment due to unexpected adverse events. Given the low accuracy of the findings, the results were considered inconclusive.

\footnotetext{
Recommendation 6

In patients with active axSpA, we strongly recommend to initiate NSAI Ds at full dosage over low dosage, because they exhibit a tendency for greater efficacy in achieving ASAS 20, reduction of morning stiffness, BASDAl, pain, patient global assessment of disease activity, and BASFI. We conditionally recommend that the full dosages of NSAIDs should be maintained, with adequate monitoring, until good disease control is achieved. Quality of evidence: low; Degree of agreement: $\mathbf{9 . 4}$
}

\section{For how long should we wait for initial response to NSAIDs in axSpA?}

The traditional NSAIDs and iCOX2 trials have shown that pain and stiffness measures differed from placebo in the first week and the maximum effect was achieved from 2 to 4 weeks. The majority of the studies had a short duration of 2 to 6 weeks [44-48]. The two trials with an extension phase from 6 to 52 weeks did not show any additional effect size with the use of NSAIDs after 6 weeks [46, 48].

The panelists considered a period of 2 weeks too short to evaluate efficacy and recommended a 4-week period as a reasonable time to change treatment, if no response is observed. Based on the previous guidelines for the treatment of axSpA and the clinical experience, despite lack of evidence, the panel recommended a second NSAI $\mathrm{D}$, regardless therapeutic class (selective COX-2 or not), could be used if the first one failed after 4 weeks. The total treatment period with NSAIDs should not exceed 12 weeks, if the predefined target is not achieved [6, 7].

\section{Recommendation 7 \\ In patients with active axSpA, in the absence of a response to the first NSAID at 4 weeks, we conditionally recommend switching to a second traditional NSAID or iCOX2. If the therapeutic target is not reached with the use of NSAIDs for 12 weeks, we strongly recommend to start an immunobiologic agent. Quality of evidence: low to high; Degree of agreement: 8.6}

\section{Continuous or on-demand use}

Is there any significant difference in the reduction of disease activity or safety of NSAIDs when comparing the on-demand versus continuous use for the treatment of axSpA?

Only two RCTs compared continuous and on-demand use of NSAIDs in AS patients. In both studies, the primary outcome was radiographic progression. Wanders et al. [69] evaluated celecoxib continuously or on demand in 215 patients with AS, and disease activity rates were reported as a secondary outcome. After 2 years, there was no significant difference of BASDAI, PGA, overall pain, or C-reactive protein serum levels between two ways of prescribing NSAIDs. More recently, Sieper et al. evaluated 167 patients with AS and compared the continuous or ondemand use of diclofenac. Although not significant, the BASDAI decreased from 4.1 to 2.7, in continuous group, and from 4.2 to 3.2 in on-demand group [70]. Regarding adverse events, there was no difference between continuous and on-demand use in either study.

Despite the lack of evidence, the panel recommended continuous use of NSAIDs in active disease until symptoms relief is achieved, based on the previous guidelines and the clinical experience $[6,7,71]$.

\section{Recommendation 8}

In patients with active axSpA, we conditionally recommend to start continuous over on-demand NSAIDs until symptoms relief is achieved. After clinical improvement or the clinical target (low disease activity or remission) has been achieved, the treatment regimen can be switched to on-demand strategy. Before prescribing continuous NSAIDs, it is important to take into account patient's opinion, comorbidities and risk factors. Quality of evidence: very low to moderate; Degree of agreement: 9.4

\section{Radiographic progression}

Is there evidence that NSAIDs can delay or minimize the progression of axial damage in axSpA? Should we switch to an immunobiologic agent in asymptomatic patients with radiographic progression?

Only the two previously cited RCTs had the reduction of radiographic progression through modified Stoke 
Ankylosing Spondylitis Spine Score (mSASSS) as the primary outcome. Over a two-year follow-up, Wanders et al. observed higher progression in the on-demand group $(+1.5 \pm 2.5)$ compared to the continuous-use group $(+0.4 \pm 1.7) \quad(p=0.002) \quad$ [69]. This result was similarly found in previous retrospective studies [72, 73]. However, a post-hoc analysis of the Wanders et al. trial showed a significant difference only in those with elevated CRP, which brought into discussion if celecoxib reduced the radiographic progression due to the reduction of inflammation instead of a specific drug class effect [74].

On the other hand, Sieper et al. did not find any significant difference on radiographic progression between the continuous and on-demand use of diclofenac over 2 years using mSASSS as outcome [70]. Numerically, the progression was higher in continuous group compared to on-demand group $(+1.3 ; 95 \%$ CI 0.7 to $1.9 \mathrm{vs}+0.8 ; 95 \%$; CI 0.2 to 1.4 , respectively), but there was no statistical significance, even when considering subgroups with the worst prognosis, such as those with higher CRP and previous syndesmophytes. Therefore, the efficacy of NSAIDs in preventing radiographic damage remains an open question. Nowadays, there is growing evidence that immunobiologic agents may reduce long-term radiographic progression, especially after 4 years of treatment. However to date, the benefit of starting an immunobiologic agent in patients with radiographic progression measured by mSASSS, but with a good symptom control with NSAID was not addressed [75-77].

\begin{abstract}
Recommendation 9
Regarding the radiographic progression, we conditionally recommend continuous over on demand use of NSAIDs in patients with active axSpA. Considering controversial results among the studies, we conditionally recommend switching to on demand strategy in inactive disease. We conditionally recommend against switching NSAIDs to immunobiological therapy when there is radiographic progression without evidence of disease activity, because the risk/benefit ratio of starting an immunobiologic agent in this scenario is not clear. Quality of evidence: very low; Degree of agreement: $\mathbf{8 . 2}$
\end{abstract}

\section{Comparison among NSAIDs}

Is there any difference regarding the efficacy of traditional NSAID versus another traditional NSAID or versus iCOX2 in patients with axSpA? Is there any difference among NSAIDs regarding adverse events in patients with axSpA?

Twenty-six RCTs compared different traditional NSAI Ds in patients with axSpA. A total of 2176 participants aged 35 to 46 years were evaluated. The overall risk of bias in these studies was considered high due to lack of information on randomization, allocation concealment, blinding, and loss to follow-up. Given the data heterogeneity, a meta-analysis was not possible $[46,51-53$, 78-95].
Seven trials compared traditional NSAIDs on pain reduction (VAS 0-100 $\mathrm{mm}$ ) and some statistically significant differences were observed [46, 51, 78, 86, 9698]: aceclofenac was inferior to indomethacin [SMD: 1.23; (95\% CI: 0.98 to 1.47)], piroxicam was superior to naproxen [SMD: -1.25 ; (95\% CI: -1.98 to -0.51$)$ ], and diclofenac was superior to sulindac [SMD: -0.54 ; $(95 \% \mathrm{CI}:-1.06$ to $-0.03)$. However, no significant difference was observed using a Likert pain scale. Two studies $[46,93,99]$ measured the PGA, and only one [93] evaluated the proportion of patients with $\geq 50 \%$ pain improvement. However, none of them found significant differences in comparison among traditional NSAIDs (piroxicam vs. meloxicam and ketoprofen vs. phenylbutazone, respectively).

A network meta-analysis, that included 26 RCTs and 3410 patients with AS, did not find any significant difference among 18 different traditional NSAIDs in shortterm (between 2 and 12 weeks) [25].

To compare coxibs and nonselective NSAIDs, seven studies were evaluated [38, 40,41, 44, 45, 48, 49]. Two RCTs used etoricoxib [41, 48], and the others with celecoxib [38, 40, 44, 45, 49]. Three RCTs used diclofenac as comparator, another three used naproxen, and the last used ketoprofen. The meta-analyses did not show significant differences between $\mathrm{iCOX} 2$ and traditional NSAIDs for pain VAS 0-100 mm score (Fig. 3), BASDAI, PGA, the proportion of patients who achieved ASAS20, or BASFI. Only the study by van der Heijde et al. found a slight superiority of etoricoxib $90 \mathrm{mg} /$ day over naproxen $1000 \mathrm{mg} /$ day for the outcomes pain VAS $0-100 \mathrm{~mm}$ and PGA. This same study found no significant difference regarding BASDAI, BASFI, or ASAS partial remission [48].

In the network meta-analysis by Wang et al., 18 traditional NSAIDs and two iCOX2 agents were compared to each other in treatment of AS. Etoricoxib was superior to celecoxib, ketoprofen, and tenoxicam with regard to pain reduction, but without a significant difference in the duration of morning stiffness. The superiority of etoricoxib should be interpreted with caution because it was based on only one RCT $[25,48]$.

Regarding any adverse events, there was no significant difference among traditional NSAIDs. In only one of the 19 studies, indomethacin caused more adverse events than oxaprozin [80]. In the analysis by organ system, indomethacin was also associated with a higher rate of neurological adverse events than aceclofenac, oxaprozin, and diclofenac $[80,83,86]$. No difference was observed in adverse events rate (renal, cardiovascular, hepatic, hematological, respiratory, or dermatologic) in patients with axSpA.

In comparison between iCOX2 and traditional NSAIDs, the meta-analysis did not detect differences for any adverse events. In the evaluation by organ system (Fig. 4a and b), there were also no significant differences, except for 


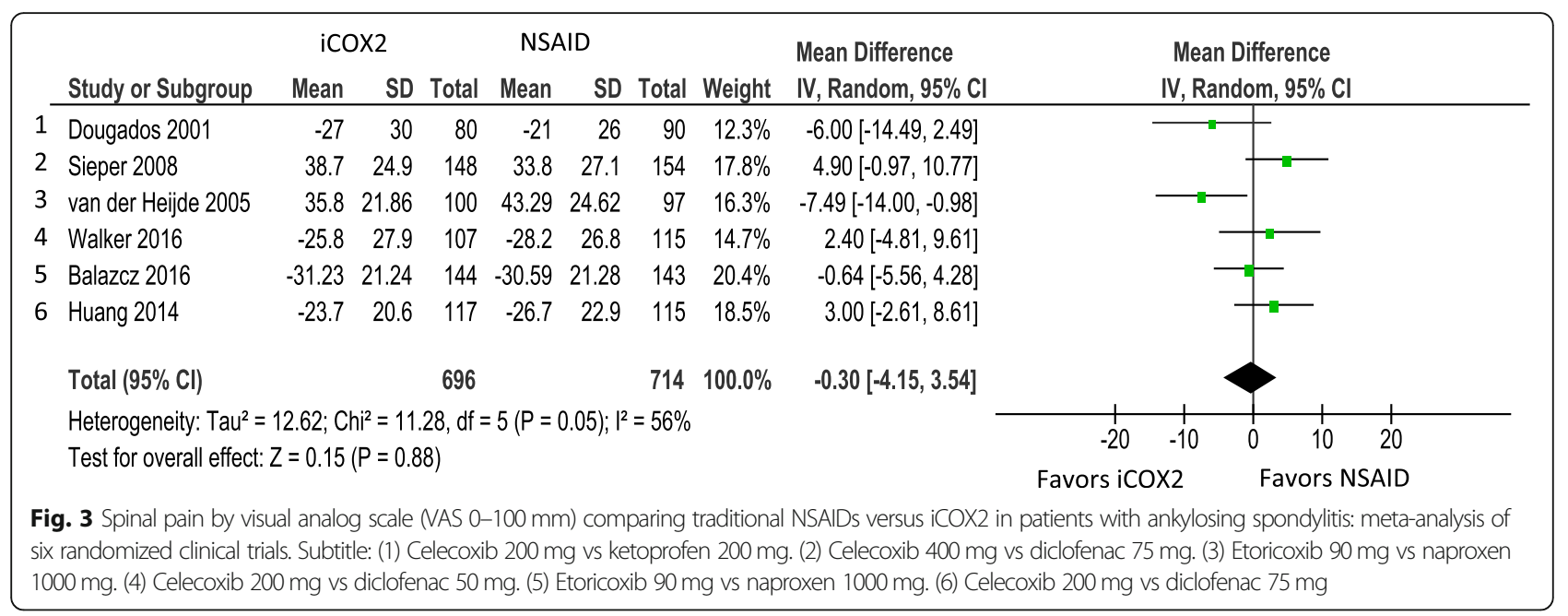

increased hepatic toxicity for iCOX2. However, this finding was highly imprecise and at the limit of statistical significance. Regarding discontinuation of treatment due to adverse events, there were no differences in the comparison of traditional NSAIDs or in the comparison between these and iCOX2. Systematic reviews that included several diseases showed greater gastrointestinal safety of iCOX2 compared to traditional NSAIDs and suggested a greater cardiovascular safety of naproxen compared to other NSAIDs [100, 101]. However, we did not observe any significant difference in the present meta-analysis (see supplementary material).

\section{Recommendation 10}

In patients with active axSpA, we conditionally recommend that the choice of a specific NSAID should be based on patient's profile (age, prior toxicity, comorbidities) and on shared decision making. To date, there is no consistent evidence of efficacy and safety differences among the NSAIDs (non-selective or iCOX2) in axSpA. Quality of evidence: low; Degree of agreement: 9.6

\section{Safety and adverse reactions \\ Is there any evidence that NSAIDs carry an increased risk of adverse events in patients with axSpA?}

Five studies compared non-selective NSAIDs versus placebo regarding adverse events, totaling 1289 patients evaluated [44-48]. The meta-analysis showed no significant adverse events differences compared to placebo. Furthermore, there was no significant serious adverse events difference or in the discontinuation rate due to adverse events in short-term (6-12 weeks) (Table 3 and Fig. 5). Another 52-week study found no significant adverse event difference among piroxicam $20 \mathrm{mg}$, meloxicam $15 \mathrm{mg}$, and meloxicam $22.5 \mathrm{mg}$ compared to placebo in $473 \mathrm{pa}-$ tients with AS (26, 38, 34, and 36\%, respectively) [46].

Considering iCOX2, three studies compared the incidence of any adverse events versus placebo in 700 patients with axSpA [44, 45, 48]. Our meta-analysis did not show any significant short-term differences (incidence of any adverse events, serious adverse events, or discontinuation of treatment due to adverse events for iCOX2 compared to placebo) (Table 3 and Fig. 6). In the single RCT with a longer followup period (52 weeks), the placebo group was blindly reallocated to receive etoricoxib $90 \mathrm{mg}$, etoricoxib $120 \mathrm{mg}$, or naproxen $1000 \mathrm{mg}$ after 6 -week follow-up. In the first 6 weeks, the rates of any adverse events were 39.8, 47.6, 48.9, and $41.4 \%$ for placebo, etoricoxib $90 \mathrm{mg}$, etoricoxib $120 \mathrm{mg}$, and naproxen, respectively. At the end of 1 year, there were no significant differences in any of the adverse events among the three groups (43.5\%, 36.1, and 38.5\%, respectively), nor in severe adverse events $(7.6,7.2$, and $7.7 \%$, respectively) or discontinuation rate due to adverse events $(8.7,4.8$, and $7.7 \%$, respectively) [48].

Therefore comparing NSAIDs versus placebo, we did not find statistical differences in the overall incidence of adverse events, which suggests a good safety profile. However, considering specific organ system analyses showed in the following sections, caution is recommended when using NSAIDs, especially regarding gastrointestinal events.

\footnotetext{
Recommendation 11

Regarding safety, in patients with active axSpA, we strongly recommend treatment with NSAIDs over no treatment, because the available

evidence showed an overall good safety profile of these drugs in axSpA. We conditionally recommend that NSAIDS should be used with caution in individuals with risk factors (age > 65 years old, diabetes mellitus, use of aspirin, corticosteroids and other platelet antiaggregants, renal or liver diseases). The risks and benefits of starting them should be shared and individualized according to the patient's risk profile. Quality of evidence: low, Degree of agreement: $\mathbf{9 . 0}$
}

\section{Is the use of NSAIDs associated with increased gastrointestinal risk in patients with axSpA?}

Five studies compared traditional NSAIDs versus placebo regarding gastrointestinal adverse events in 1289 patients [44-48]. The frequency of gastrointestinal 
a

ICOX2 NSAID Risk Ratio

Study or Subaroup Events Total Events Total Weight $\mathrm{M}-\mathrm{H}, \mathrm{Random}, 95 \% \mathrm{Cl}$

3.16.1 Cardiovascular events

lar events

2 Huang 2014

Subtotal $(95 \% \mathrm{Cl})$

Total events

$\begin{array}{lllll}0 & 120 & 1 & 120 & 0.6 \%\end{array}$

$0.16[0.01,2.96]$

$0.33[0.01,8.10]$

$0.22[0.03,1.93]$

Heterogeneity: $\mathrm{Tau}^{2}=0.00 ; \mathrm{Ch}^{2}=0.12, \mathrm{df}=1(P=0.73) ; \mathrm{i}^{2}=0 \%$

Test for overall effect: $Z=1.37(P=0.17)$

3.16.2 Gastrointestinal events

$\begin{array}{lllll}21 & 161 & 29 & 157 & 9.5 \%\end{array}$

4 Dougados 2001

5 Sieper 2008

6 van der Heijde 2005

7 Huang 2014

Walker 2016

$\begin{array}{lr}27 & 80\end{array}$

$\begin{array}{rrr}29 & 90 & 10.9 \% \\ 44 & 155 & 10.8 \%\end{array}$

$\begin{array}{lllll}25 & 150 & 44 & 155 & 10.8 \%\end{array}$

$\begin{array}{rrrrr}13 & 103 & 5 & 99 & 4.5 \% \\ 3 & 120 & 4 & 120 & 2.4 \%\end{array}$

Subtotal $(95 \% \mathrm{Cl})$

$\begin{array}{rrrrr}3 & 120 & 4 & 120 & 2.4 \% \\ 36 & 107 & 40 & 115 & 12.0 \%\end{array}$

Total events

721

$\begin{array}{ll}115 & 12.0 \% \\ 736 & 50.0 \%\end{array}$

125

151

Tau $=0.06 ; \mathrm{Chi}^{2}=9.16$, df $=5(P=0.10) ; l^{2}=45 \%$

Test for overall effect: $Z=0.78(P=0.44)$

3.16.3 Hepatic events

9
10

Sieper 2008

Huang 2014
Subtotal $(95 \% \mathrm{Cl})$

Total events

$\begin{array}{lllll}0 & 150 & 6 & 155 & 0.7 \%\end{array}$

$\begin{array}{llll}150 & 6 & 155 & 0.7 \% \\ 120 & 2 & 120 & 0.6 \% \\ 270 & & 275 & 1.4 \%\end{array}$

270

$275 \quad 1.4 \%$

Test for overall effect: $Z=1.97(P=0.05)$

3.16.4 Respiratory events

12 Dougados 2001

13 Sieper 2008

14 van der Heijde 2005

Huang 2014

Subtotal $(95 \% \mathrm{Cll})$

Total events

$\begin{array}{lllll}14 & 161 & 16 & 157 & 7.3 \%\end{array}$

$\begin{array}{lllll}5 & 80 & 9 & 90 & 4.2 \%\end{array}$

$\begin{array}{lllll}9 & 150 & 6 & 155 & 4.4 \%\end{array}$

$\begin{array}{lllll}1 & 103 & 2 & 99 & 1.0 \%\end{array}$

$\begin{array}{lllll}1 & 120 & 0 & 120 & 0.6 \%\end{array}$

30

33

Heterogeneity: $\operatorname{Tau}^{2}=0.00 ; \mathrm{Chi}^{2}=2.41, \mathrm{df}=4(\mathrm{P}=0.66) ; 1^{2}=0 \%$

Test for overall effect: $Z=0.34(P=0.74)$

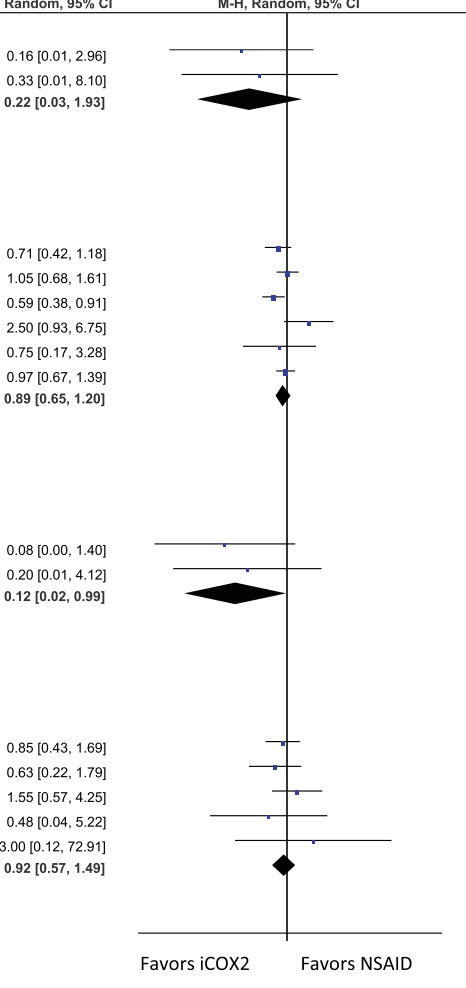

b

iCOX2 NSAID

Risk Ratio

Study or Subgroup Events Total Events Total Weight M-H, Random, $95 \% \mathrm{Cl}$

Risk Ratio
$\mathrm{Cl}$
$\mathrm{M}-\mathrm{H}$, Random, $95 \% \mathrm{Cl}$

16

3.16.5 Hematologic events

.16.5 Hematologic events

$\begin{array}{lrrrrrr}\text { Huang } 2014 & 0 & 80 & 1 & 90 & 0.6 \% & 0.37[0.02,9.06]\end{array}$

$\begin{array}{llllllll} & 1 & 120 & 0 & 120 & 0.6 \% & 3.00[0.12,72.91]\end{array}$

$\begin{array}{llll}\text { Total events } & 1 & 1 & 1.2 \%\end{array}$

Heterogeneity: $\operatorname{Tau}^{2}=0.00 ; \mathrm{Chi}^{2}=0.82$, df $=1 \quad(P=0.37) ; 1^{2}=0 \%$

Test for overall effect: $Z=0.05(P=0.96)$

3.16.6 Neurological events

Barkhuizen $2006 \quad 13$

\begin{tabular}{llllll}
\hline & 6 & 157 & $3.2 \%$
\end{tabular}

$\begin{array}{lllll}23 & 150 & 39 & 155 & 10.3 \%\end{array}$

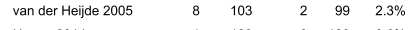

$120 \quad 0 \quad-120 \quad 00 \%$

Subtotal $(95 \% \mathrm{Cl})$

107

$\begin{array}{ll}120 & 0.6 \% \\ 115 & 4.0 \% \\ 736 & 23.2 \%\end{array}$

$\begin{array}{lrr}8 & 115 & 4.0 \% \\ 736 & 23.2 \%\end{array}$ 56

55

Heterogeneity: $\mathrm{Tau}^{2}=0.66 ; \mathrm{Chi}^{2}=15.22$, df $=5(P=0.009) ; \mathrm{I}^{2}=67 \%$

Test for overall effect: $Z=1.02(P=0.31)$

\subsubsection{Dermatologic events}

24 Barkhuizen 2006

25 Dorgat

26 Huang 2014

$\begin{array}{lllll}8 & 161 & 0 & 157 & 0.7 \%\end{array}$

$\begin{array}{lllll}4 & 80 & 3 & 90 & 2.4 \%\end{array}$

$\begin{array}{lllll}1 & 120 & 0 & 120 & 0.6 \%\end{array}$

$\begin{array}{rr}3 & 107 \\ & 468\end{array}$

$\begin{array}{ll}115 & 1.8 \% \\ 482 & 5.5 \%\end{array}$

Subtotal (95\% Cl)

16

5

$3.00[0.12,72.91]$
$1.06[0.11,10.09]$

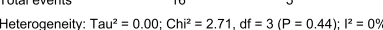

Test for overall effect: $Z=1.56(P=0.12)$

Total $(95 \% \mathrm{Cl})$
Total events 228 3164

Heterogeneity: $\mathrm{Tau}^{2}=0.10 ; \mathrm{Chi}^{2}=38.38, \mathrm{df}=26(\mathrm{P}=0.06) ; \mathrm{I}^{2}=32 \%$ Test for overall effect: $Z=0.24(P=0.81)$

Test for subgroup differences: $\mathrm{Ch}^{2}=9.72$, of $=6(P=0.14), 1^{2}=38.3 \%$

$16.58[0.97,284.85]$

$1.50[0.35,6.50]$

$3.00[0.12,72.91]$

$1.61[0.27,9.46]$

$2.21[0.81,5.98]$

$4.23[1.23,14.54]$
$2.25[0.58,8.70]$

$0.61[0.38,0.97]$

$3.84[0.84,17.66]$

$3.00[0.12,72.91]$
$0.67[0.23,1.99]$

$56[0.67,3.64]$

M-H, Random, $95 \% \mathrm{Cl}$

Fig. 4 (See legend on next page.) 
(See figure on previous page.)

Fig. $\mathbf{4} \mathbf{a}$ and $\mathbf{b}$ Incidence of adverse events per organ system in the comparison of COX2 selective inhibitors versus traditional NSAIDs in patients with ankylosing spondylitis: meta-analyses of seven randomized clinical trials. Subtitle: (1) Celecoxib $400 \mathrm{mg}$ vs diclofenac $75 \mathrm{mg}$. (2) Celecoxib $200 \mathrm{mg}$ vs diclofenac $75 \mathrm{mg}$ (3) Celecoxib $400 \mathrm{mg}$ vs naproxen $500 \mathrm{mg}$. (4) Celecoxib $200 \mathrm{mg}$ vs ketoprofen $200 \mathrm{mg}$. (5) Celecoxib $400 \mathrm{mg}$ vs diclofenac 75 mg. (6) Etoricoxib 90 mg vs naproxen 1000 mg. (7) Celecoxib 200 mg vs diclofenac 75 mg. (8) Celecoxib 200 mg vs diclofenac 50 mg (9) Celecoxib $400 \mathrm{mg}$ vs diclofenac $75 \mathrm{mg}$. (10) Celecoxib $200 \mathrm{mg}$ vs diclofenac $75 \mathrm{mg}$. (11) Celecoxib $400 \mathrm{mg}$ vs naproxen $500 \mathrm{mg}$. (12) Celecoxib $200 \mathrm{mg}$ vs ketoprofen 200 mg. (13) Celecoxib 400 mg vs diclofenac 75 mg. (14) Etoricoxib 90 mg vs naproxen 1000 mg. (15) Celecoxib 200 mg vs diclofenac $75 \mathrm{mg}$ (16) Celecoxib $200 \mathrm{mg}$ vs ketoprofen $200 \mathrm{mg}$. (17) Celecoxib $200 \mathrm{mg}$ vs diclofenac $75 \mathrm{mg}$. (18) Celecoxib $400 \mathrm{mg}$ vs naproxen 500 mg. (19) Celecoxib $200 \mathrm{mg}$ vs ketoprofen $200 \mathrm{mg}$. (20) Celecoxib $400 \mathrm{mg}$ vs diclofenac $75 \mathrm{mg}$. (21) Etoricoxib $90 \mathrm{mg}$ vs naproxen $1000 \mathrm{mg}$. (22) Celecoxib $200 \mathrm{mg}$ vs diclofenac $75 \mathrm{mg}$. (23) Celecoxib $200 \mathrm{mg}$ vs diclofenac $50 \mathrm{mg}$ (24) Celecoxib $400 \mathrm{mg}$ vs naproxen 500 mg. (25) Celecoxib $200 \mathrm{mg}$ vs ketoprofen $200 \mathrm{mg}$ (26) Celecoxib $200 \mathrm{mg}$ vs diclofenac 75 mg. (27) Celecoxib $200 \mathrm{mg}$ vs diclofenac 50 mg

events was higher with tranditional NSAIDs than placebo. A similar result was observed with iCOX2 in 769 patients when compared to placebo (Table 3, Figs. 7 and 8) [44, 45, 48]. There was no significant difference in the metaanalysis of six RCTs that compared iCOX2 versus traditional NSAIDs $(\mathrm{RR}=0.89 ; 0.65-1.2)$. Most $\mathrm{RCTs}$ were short-term (2-12 weeks) [38, 40, 44, 45, 48, 49].

In the Dougados' study (1999), the extension phase lasted from 6 th to 52 nd week. In the first 6 weeks, the authors showed 14\% gastrointestinal events with traditional NSAIDs versus $7 \%$ in placebo group. A total of six (1.7\%) individuals from NSAID group had gastroduodenal ulcers, and no patients were diagnosed in placebo group by week 52 [46]. Regarding iCOX2, only the RCT by van der Heijde et al. (2005) analyzed adverse events from week 6 to week 52 in the extension phase, not controlled by placebo. The incidence of pyrosis after 1 year of use was 9.8, 7.2, and 7.7\% for etoricoxib $90 \mathrm{mg}$, etoricoxib $120 \mathrm{mg}$, and naproxen 1000 $\mathrm{mg}$, respectively. Three (2.4\%) patients who received etoricoxib $120 \mathrm{mg}$ and 4 (3.2\%) who received naproxen had gastroduodenal ulcers at 1 year of follow-up [48].

Most data on gastrointestinal risk were from studies in other populations (osteoarthritis, rheumatoid arthritis, etc.) and there is no evidence that the risk is different in axSpA. Factors considered high-risk for gastrointestinal complications with NSAIDs are age above 65 years, comorbidities (diabetes, COPD, coronary disease, coagulopathies), alcoholism, concomitant medication (corticosteroids, anticoagulants, aspirin, other antiplatelet aggregation drugs), history of peptic ulcer, and Helicobacter pylori infection. An observational study that evaluated 4144 individuals with osteoarthritis (85\%), rheumatoid arthritis (11\%), or AS (3\%) and at least one gastrointestinal risk factor, with a mean follow-up of 6 months, showed an incidence of 0.7 severe events per 100 patients-year after the initiation of NSAIDs. The associated use of gastroprotective drugs, such as proton pump inhibitors, reduced the risk in approximately $30 \%$ of patients $[100,102,103]$. Systematic reviews that included several diseases, not restricted to the population with SpA, showed greater gastrointestinal safety of iCOX2 [100, 101], but we did not find any significant difference between iCOX2 and traditional NSAIDs in the present meta-analysis (see Fig. 4a and Supplementary Material).

\footnotetext{
Recommendation 12

In patients with active axSpA, we conditionally recommend to avoid NSAIDs (non-selective or iCOX2) and to start an immunobiologic agent in those with current or previous peptic ulcer or gastrointestinal bleeding.

We conditionally recommend the use of an iCOX2 agent over a traditional NSAID in patients with gastrointestinal risk factors.

We strongly recommend the use of concomitant gastroprotective drugs in symptomatic or high-risk patients. Quality of evidence: low; Degree of agreement: $\mathbf{8 . 9}$
}

\section{Is the use of NSAIDs associated with increased cardiovascular risk in axSpA?}

There is growing evidence that $\mathrm{SpA}$ is associated with increased mortality, especially for cardiovascular diseases,

Table 3 Incidence of adverse events associated with traditional NSAIDs or iCOX2 compared to placebo in patients with axSpA: meta-analysis of randomized clinical trials

\begin{tabular}{|c|c|c|}
\hline & $\begin{array}{l}\text { TRADITIONAL NSAIDs } \\
N=1289\end{array}$ & $\begin{array}{l}\text { iCOX2 } \\
N=669\end{array}$ \\
\hline Adverse events & $\begin{array}{l}35.6 \% \text { vs } 36.4 \%(\mathrm{PbO}) \\
\mathrm{RR}=1.08(0.93 \text { to } 1.25)\end{array}$ & $\begin{array}{l}54.6 \% \text { vs } 46.4 \%(\mathrm{PbO}) \\
\mathrm{RR}=1.22(0.93 \text { to } 1.62)\end{array}$ \\
\hline Severe adverse events & $\begin{array}{l}1 \% \text { vs } 0.6 \%(\mathrm{PbO}) \\
\mathrm{RR}=1.71(0.37 \text { to } 8.01)\end{array}$ & $\begin{array}{l}0.6 \% \text { vs } 0.6 \%(\mathrm{PbO}) \\
\mathrm{RR}=0.96(0.17 \text { to } 5.53)\end{array}$ \\
\hline Gastrointestinal adverse events & $\begin{array}{l}18 \% \text { vs } 9.5 \%(\mathrm{PbO}) \\
\mathbf{R R}=\mathbf{1 . 9 2}(\mathbf{1 . 4 1} \text { to } \mathbf{2 . 6 1 )}\end{array}$ & $\begin{array}{l}17.7 \% \text { vs } 7.5 \%(\mathrm{PbO}) \\
\mathbf{R R}=\mathbf{2 . 5 5}(\mathbf{1 . 9 2} \text { to } \mathbf{4 . 9 5 )}\end{array}$ \\
\hline Discontinuation due to adverse events & $\begin{array}{l}5 \% \text { vs } 5.5 \%(\mathrm{PbO}) \\
\mathrm{RR}=0.76(0.48 \text { to } 1.22)\end{array}$ & $\begin{array}{l}4.6 \% \text { vs } 3.4 \%(\mathrm{PbO}) \\
\mathrm{RR}=2.14(0.36 \text { to } 12.56)\end{array}$ \\
\hline
\end{tabular}




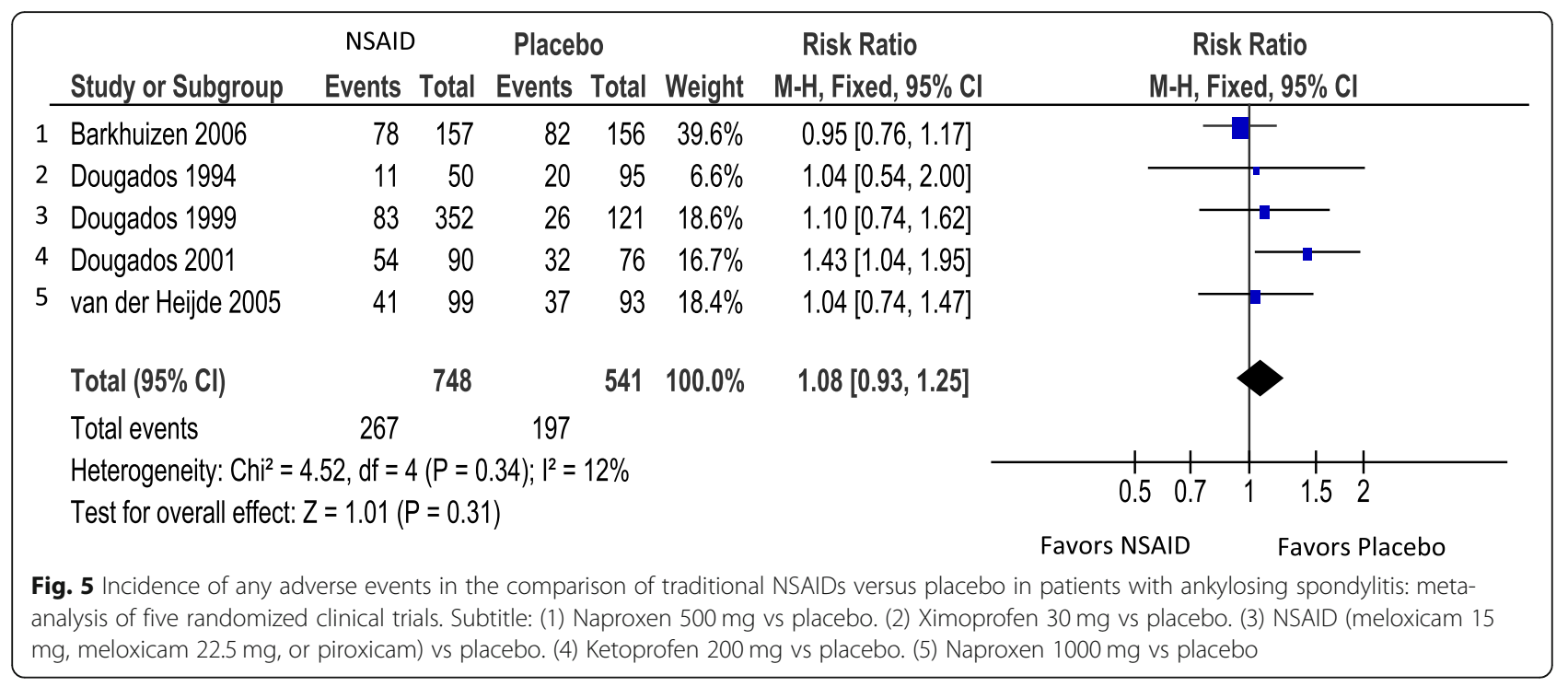

due to multiple factors such as chronic inflammation, associated comorbidities and maybe the drugs used to treat these patients [104-107]. Regarding NSAIDs, large population studies, including a Danish cohort of more than 1 million individuals, suggested 2 to 3 -fold increase regarding cardiovascular risk (acute myocardial infarction, stroke, and death from cardiovascular disease) with the chronic use of iCOX2 or nonselective NSAIDs, except for naproxen. Meta-analysis of observational studies estimates an absolute risk of major adverse cardiovascular events (MACE) of approximately 3 per 1000 patients-year with the use of NSAIDs [100, 101, 108, 109]. Furthermore, NSAIDs have been shown to increase mortality in the first 3 to 6 months after acute cardiovascular events $[110,111]$.

However, in the population with SpA, the relationship of NSAIDs with cardiovascular mortality risk is less clear. Debreuil et al., in a case-control study using a large British database, compared the incidence of acute myocardial infarction (AMI) between a cohort of SpA patients with a cohort of osteoarthritis (OA) patients. Current use of diclofenac (0-180 days prior to index date) compared to remote use (more than 365 days prior to index date) was associated with an increased risk of AMI both in SpA group [adjusted $\mathrm{OR}=3.32$ (95\% CI 1.57 to 7.03$)$ ] and $\mathrm{OA}$ group [(ORa $=1.26$ (95\% CI 1.14 to 1.39)]. Additionally, the risk was different between the two groups [ORa ratio $=2.64$ (95\% CI 1.24 to 5.58 , OA as reference)], whereas there was no increased risk of AMI when naproxen was analyzed, either in patients with $\mathrm{SpA}[(\mathrm{ORa}=1.19(95 \% \mathrm{CI}$ 0.53 to 2.68)] or in those with OA [112]. Interestingly, other authors have observed a protective effect of NSAIDs against cardiovascular events in patients with axSpA. Haroon et al. studied 21,143 patients with AS compared to 86,606 controls, based on Canadian database, observed a hazard ratio (HR) of 1.36 (95\% CI 1.13 to 1.65) for a composite outcome of cardiovascular death. A subgroup analysis of patients older than 65 years demonstrated a protective effect of conventional NSAIDs for

\begin{tabular}{|c|c|c|c|c|c|c|c|c|c|c|c|c|}
\hline & \multirow[b]{2}{*}{ Study or Subgroup } & \multicolumn{2}{|c|}{ icox2 } & \multicolumn{3}{|c|}{ Placebo } & \multirow{2}{*}{$\begin{array}{c}\quad \text { Risk Ratio } \\
\text { M-H, Random, } 95 \% \mathrm{Cl}\end{array}$} & \multirow{2}{*}{\multicolumn{3}{|c|}{$\begin{array}{c}\text { Risk Ratio } \\
\text { M-H, Random, } 95 \% \mathrm{Cl}\end{array}$}} & & \\
\hline & & Events & Total & Events & Total & Weight & & & & & & \\
\hline 1 & 1 Barkhuizen 2006 & 85 & 161 & 82 & 156 & $38.8 \%$ & $1.00[0.82,1.24]$ & \multicolumn{5}{|c|}{+} \\
\hline 2 & 2 Dougados 2001 & 54 & 80 & 32 & 76 & $31.2 \%$ & $1.60[1.18,2.17]$ & & & $\longrightarrow$ & & \\
\hline \multirow[t]{5}{*}{3} & 3 van der Heijde 2005 & 49 & 103 & 37 & 93 & $29.9 \%$ & $1.20[0.87,1.65]$ & & & & & \\
\hline & Total $(95 \% \mathrm{Cl})$ & & 344 & & 325 & $100.0 \%$ & $1.22[0.93,1.62]$ & & & & & \\
\hline & Total events & 188 & & 151 & & & & & & & & \\
\hline & \multicolumn{7}{|c|}{ Heterogeneity: $\operatorname{Tau}^{2}=0.04 ; \mathrm{Chi}^{2}=6.19, \mathrm{df}=2(P=0.05) ; 1^{2}=68 \%$} & 0.2 & 0.5 & 1 & se & \\
\hline & \multicolumn{7}{|c|}{ Test for overall effect: $Z=1.42(P=0.16)$} & Fav & $0 \times 2$ & Favors Pla & & \\
\hline
\end{tabular}




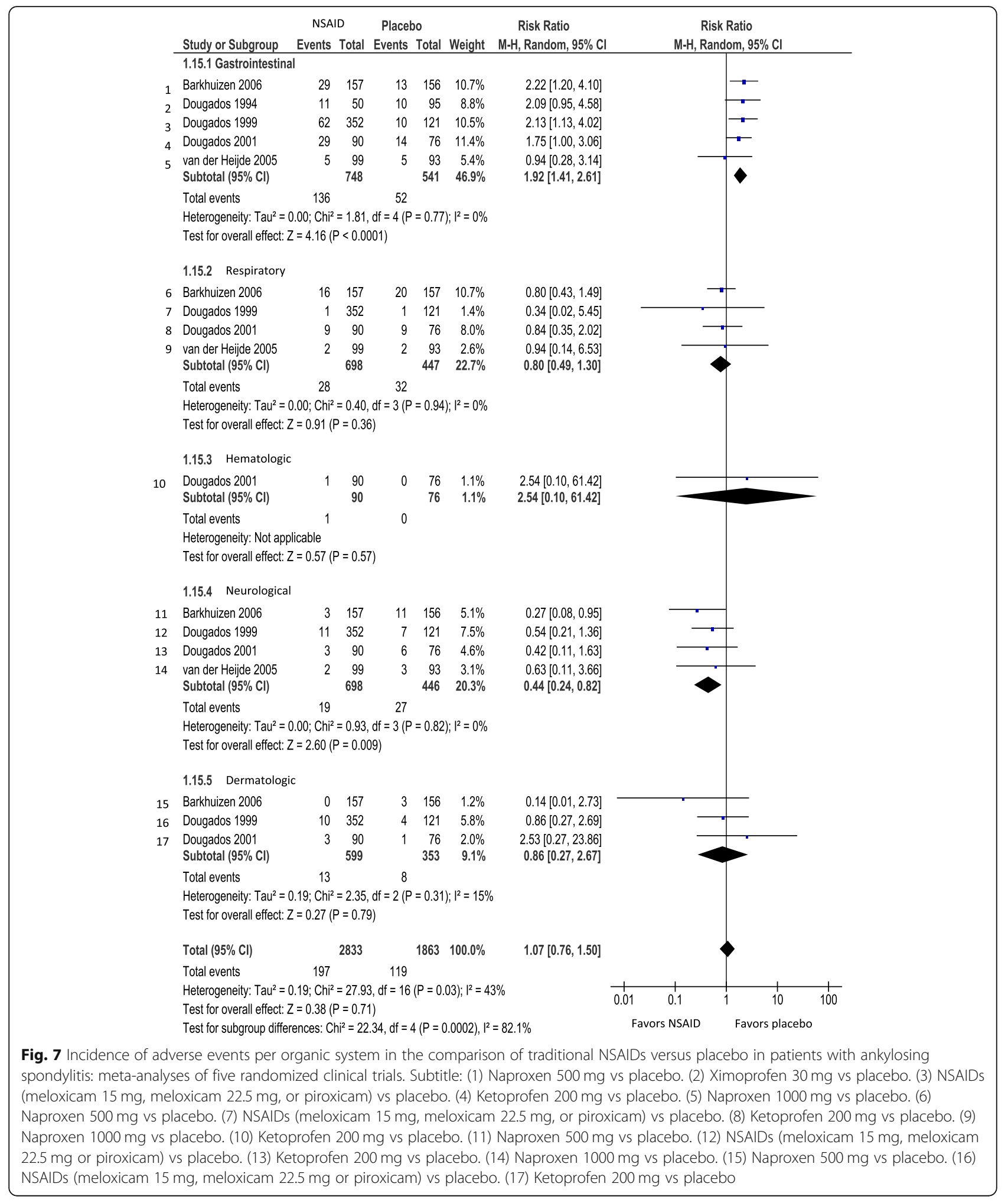

cardiovascular death [HR=0.1 (95\% CI 0.01 to 0.61)] [105]. Tsai et al., using data from the Taiwan Health Insurance, observed a reduced risk of MACE after 12 months in patients with AS who had prolonged use of NSAIDs (> $80 \%$ of the observation time) [23]. Another Taiwan case-control study found negative association between the use of celecoxib (versus non-users) and coronary events [OR $=0.34$ (95\% CI 0.13 to 0.89 )] in AS patients [26]. Other publications 


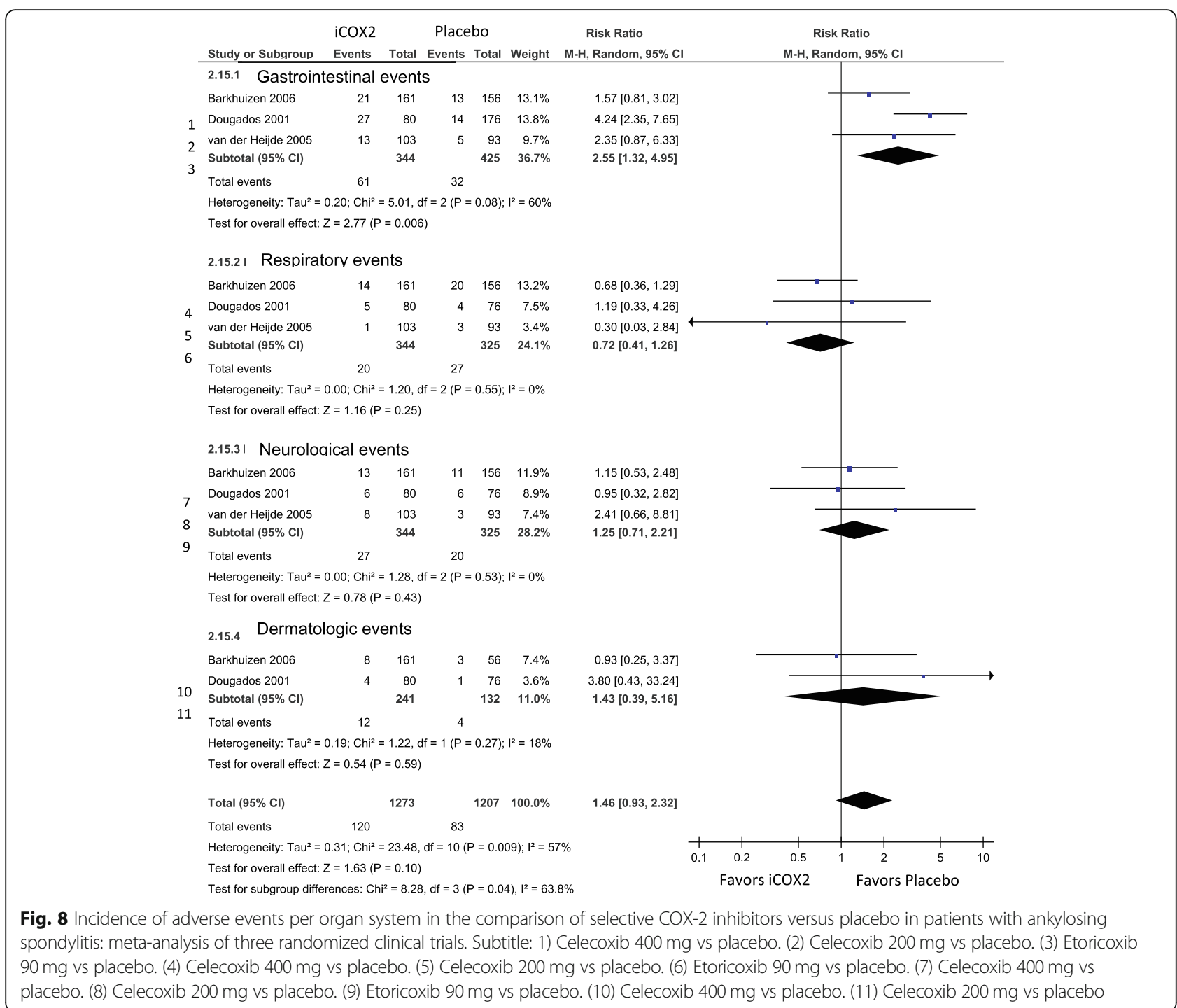

also suggest the protective effect of NSAIDs against cardiovascular events, but the data should be interpreted with caution because patients with more comorbidities and risk factors tend to be less exposed to NSAIDs $[17,106]$. In summary, it is still controversial whether the beneficial effect of reducing inflammation would outweigh the negative effects of NSAIDs per se regarding cardiovascular risk.

The present systematic review, which included only RCTs and not observational studies, did not find higher cardiovascular risk when comparing traditional NSAIDs or iCOX2 versus placebo. Two RCTs compared traditional NSAIDs versus iCOX2 on cardiovascular events incidence $[2 \%(4 / 175)$ and $0 \%(0 / 170)$, respectively] and no significant difference in meta-analysis $[R R=0.22$ (95\% CI 0.03 to 1.93$)$ ] was observed [38, 49].

Furthermore, the panel decided to conditionally recommend caution when prescribing NSAIDs in patients with cardiovascular risks factors, specially in those with a recent myocardial infarction or stroke.

\section{Recommendation 13 \\ In patients with active axSpA, we conditionally recommend to avoid NSAID therapy and to start an immunobiologic agent in those with cardiovascular risk factors, mainly in those with previous acute myocardial infarction or stroke, especially if recent (past 12 months). Quality of evidence: very low; Degree of agreement: $\mathbf{8 . 4}$}

\section{Are NSAIDs associated with increased renal risk in patients with axSpA?}

The RCTs selected for this systematic review did not report renal toxicity from NSAIDs in patients with axSpA. Similarly to the cardiovascular toxicity, the renal adverse events evidences were obtained from data including other populations. A large cohort study (183, 
446 patients; $80 \%$ women; mean age of 78 years) found an incidence of $0.5 \%$ ( 1 in 200 new treatments) of acute kidney injury (AKI), requiring hospitalization, in a period of up to 45 days after the onset of NSAIDs [113]. A meta-analysis evaluated 28,992 patients and demonstrated a RR of AKI associated with NSAIDs ranging from 1.25 to 2.21 that was statistically significant for several NSAIDs [114]. Regarding the possibility of progression to chronic kidney disease, a prospective study with 10,184 patients ( $57 \%$ women; mean age 76 years) found $\mathrm{RR}=1.26$ (95\% CI 1.04 to 1.53$)$ for a reduction of glomerular filtration rate of at least $15 \mathrm{ml} / \mathrm{min} / 1.73 \mathrm{~m}^{2}$ among NSAID users when compared with non-users during a median follow-up of 2.75 years [115].

\section{Does the use of NSAIDs increase the risk of adverse events in other organs/systems in axSpA?}

Considering five RCTs of non-selective NSAIDs versus placebo and three of iCOX2 versus placebo, neither the meta-analysis nor individual studies found an increase in respiratory, hematological, dermatologic, or neurological adverse events [44-48]. Additionally, no significant differences were found in the comparison of $\mathrm{iCOX} 2$ versus traditional NSAIDs [38, 40, 44, 45, 48, 49]. In the comparison of NSAIDs with other NSAIDs, selective or not for COX-2, only indomethacin was associated with a greater number of neurological adverse events $[80,83$, 86]. Despite data from general population have suggested some hepatotoxic effect of NSAIDs, no specific RCTs were found for NSAIDs versus placebo in patients with axSpA [116]. The current meta-analysis found greater hepatic toxicity for iCOX2 compared to nonselective NSAIDs, but with high imprecision data and at the limit of statistical significance (Figs. 7 and 8).

\footnotetext{
Recommendation 14

In patients with active axSpA, we conditionally recommend to avoid NSAIDs and to start an immunobiologic agent in thoses with increased risk of renal adverse events. The decision should be individualized and risk/benefits shared with the patient.

We strongly recommend caution and regular monitoring of renal function, especially in high-risk individuals (elderly, hypertension, diabetes, kidney dysfunction). Quality of evidence: very low; Degree of agreement: 9.4
}

\section{Conclusions}

The most recently published guidelines for the management of axSpA recommended NSAIDs as the first line treatment, but none of them has addressed specifically the current role of NSAIDs in the treatment of patients with axSpA regarding efficacy, safety and therapeutic strategy $[6,7,71]$. The present systematic review and critical analysis of the available evidences have confirmed that NSAIDs are still the basis for the treatment of patients with axSpA, as they are effective in most part of those patients.

There is no doubt that the immunobiologic agents are quite effective and brought great benefit for the management of axSpA, but they carry a high cost which demands the best rationale for prescribing them. Our recommendations, in consonance with the most important guidelines, strengthen the statement that NSAIDs are the first line treatment in patients with axSpA and they should be started as soon as the diagnosis is confirmed.

The benefit of NSAIDs in delaying radiographic progression in axSpA and if immunobiologics should be the first line treatment in patients with poor prognostic criteria (elevated CRP, smokers and those with previous syndesmophytes) remain an open question.

This review has also shown that NSAIDs have a good safety profile and are usually well tolerated for the longterm use. The concerns about the cardiovascular and renal side effects are based mostly in data from other populations, but not in patients with axSpA that are usually younger and have less comorbidities and risk factors than other NSAID's long-term or frequently users, like patients with osteoarthritis for example.

One possible limitation of these recommendations is that we did not include a patient representative in the voting panel. This strategy could be used in future guidelines.

The purpose of these guidelines was to provide recommendations elaborated by a panel of rheumatologists with expertise in the field of SpA, mainly to support clinician's decision making, without taking out his/her autonomy to choose the best therapeutic option for an individual patient.

\section{Supplementary Information}

The online version contains supplementary material available at https://doi. org/10.1186/s42358-020-00160-6.

Additional file 1

\section{Abbreviations}

AxSpA: Axial Spondyloarthritis; AS: Ankylosing Spondylitis; PsA: Psoriatic Arthritis; ASAS: Ankylosing Spondylitis Assessment Study Group;

RCT: Randomized Clinical Trial; TNFi: Tumor Necrosis Factor inhibitor; IL17i: Interleukin-17 inhibitor; NSAID: Nonsteroidal Anti-inflammatory Drug; iCOX2: Specific Cycloxigenase-2 inhibitor; BASDAl: Bath Ankylosing Spondylitis Disease Activity Index; ASDAS: Ankylosing Spondylitis Disease Activity Score; BASFI: Bath Ankylosing Spondylitis Disease Functional Index; PAIN50\%: $\geq 50 \%$ improvement in pain; MD: Mean Difference; SMD: Standard Mean Difference; CRP: C Reactive Protein; ESR: Erythrocyte Sedimentation Rate; PAIN-VAS: Pain by Visual Analogue Scale; PGA: Patient Global Assessment of disease activity; ASAS20: At least 20\% improvement according to ASAS response criteria; ASAS40: At least 40\% improvement according to ASAS response criteria; mSASSS: modified Stoke Ankylosing Spondylitis Spine Score 


\section{Acknowledgements}

We thank Haliton Alves de Oliveira Junior and Anna Maria Buehler for technical support in the systematic review, statistical assistance and for performing the meta-analyses.

\section{Authors' contributions}

All authors made contributions to the acquisition of data, have been involved in drafting the manuscript or revising it critically for important intellectual content, participated in the voting rounds, gave final approval of the version to be published and have participated sufficiently in the work to take public responsibility for appropriate portions of the content.

\section{Funding}

Brazilian Society of Rheumatology. The funding body had no role in the design of the study and collection, analysis, and interpretation of data and in writing the manuscript.

\section{Availability of data and materials}

\section{Online supplement.}

\section{Ethics approval and consent to participate} Not applicable.

\section{Consent for publication}

Not applicable.

\section{Competing interests}

Ricardo da Cruz Lage received lecture fees from Abbvie, Pfizer and Novartis; sponsorship for events from Janssen, Novartis, Pfizer and Abbvie; research payments from Abbvie.

Cláudia Diniz Lopes Marques received lecture fees from Abbvie, Janssen, Pfizer and Novartis; advisory board from Novartis and Abbvie; sponsorship for events from Abbvie, Janssen, Pfizer, Novartis, and Lilly.

Thauana Luíza Oliveira received lecturer fees from Abbvie, Novartis and Janssen; support to congresses from Abbvie and Janssen.

Gustavo Gomes Resende received lecture fees from Abbvie, Janssen, Novartis, Pfizer, and UCB; advisory board from Abbvie, Janssen, and Novartis; Research support from Brazilian Society of Rheumatology, FAPEMIG and UCB; clinical research payments from Abbvie and Pfizer; sponsorship for scientific events from Abbvie, Janssen, Lilly, Novartis, Pfizer, and UCB.

Charles Lubianca Kohen received financial support for advisory board participation from Novartis; speaker fee from Janssen, Abbvie, Novartis, Pfizer, UCB; support to events from Janssen, Abbvie, Roche, Astra-Zeneca, Novartis. Carla Gonçalves Saad has no conflicts of interest.

Antônio Carlos Ximenes received payments for participation in clinical research from Abbvvie, Pfizer, Roche, BMS, and Amgen; on scientific board of Pfizer, and Abbivie; as a lecturer from AbbVie, Pfizer, and Abbott. Célio Roberto Gonçalves has no conflicts of interest. Washington Alves Bianchi has no conflicts of interest. Eduardo de Souza Meirelles received payments as a speaker from Novartis, Abbvie, Abbott and Marjan; research grants from Novartis and Pfizer; support for conferences and courses from Aché, Pfizer, Novartis, Janssen, Abbvie, Roche, and Lilly; Advisory board fee from Novartis and Marjan. Mauro Waldemar Keiserman received financial support for lectures, advisory bord and clinical research from Abbvie, Actelion, Biogen, Bristol, Celltrion, Lilly, Human Genome Sceiences, Janssen, Pfizer, Novartis, Roche, Sanofi, and UCB.

Adriano Chiereghin received honoraria as a speaker from Janssen, Novartis, UCB, and Pfizer; support to courses and congresses from Abbvie, Janssen, Novartis, UCB, and Pfizer; advisory board from Novartis and Janssen. Cristiano Barbosa Campanholo received financial support for advisory board participation from Janssen, Abbvie, Bristol, Lilly, Novartis, Pfizer, UCB; speaker fee from Janssen, Abbvie, Lilly, Novartis, and Pfizer, UCB; support to events from Janssen, Abbvie, Bristol, Novartis, and Pfizer.

Andre Marun Lyrio received payments from Speaker of Janssen and UCB; support to courses/congresses from Janssen, Abbvie, Pfizer, UBC, Novartis, and Lily.

Cláudia Goldenstein Schainberg has participated in the pharmaceutical advisory board of AbbVie, Janssen, Lilly, Novartis, and Pfizer; is a speaker invited by AbbVie, Janssen, Lilly, Novartis, Pfizer; has no stock of these pharmaceutical industries.
Lenise Brandao Pieruccetti has no conflicts of interest.

Michel Alexandre Yazbek received financial support from Abbvie, UCB, Novartis and Lilly.

Penelope Esther Palominos has no conflicts of interest.

Rafaela Silva Guimarães Goncalves received fees for lectures from Janssen, Novertis, Abbvie, Apsen, Bristol, and Pfizer; advisory board from Janssen. Rodrigo Luppino Assad received fees for lectures and advisory board from Abbvie, Novartis, Janssen, UCB, Lilly, and Bristol; research support from Abbvie and UCB.

Rubens Bonfiglioli received financial support for clinical research from Roche, Pfizer, Amgen, and Novartis; for scientific advisory from Lilly, Abbvie, Roche, and UCB; for support to events from Roche, Pfizer, Abbvie and Novartis; for symposia and sponsored meetings from Roche, Pfizer, and Janssen. Sônia Maria Alvarenga Anti received financial support from Abbvie, Jansen, Novartis, Lilly, and UCB.

Sueli Coelho da Silva Carneiro received honorary speaker from Abbvie, Janssen, Lilly, Novartis and Pfizer; support to research from CNPq and FAPE RJ; support for congresses from Abbvie, Janssen, Novartis, Pfizer, CNPq and FAPERJ; advisory board from Janssen, Lilly, and Novartis.

Valderílio Feijó Azevedo is GRAPPA member; Medical diretor of Edumed Biotech; received for clinical research from Pfizer, Roche, Janssen, Bristol, Abbvie, Medimmune, Boehringer, GSK, USB, Sanofi, Takeda, Bird Rock Bio, and NovoNordisk; financial support to events and lectures from Pfizer, Hospira, Roche, MSD, BMS, Merck Senoro, Janssen, Novertis, Celltrion, UCB, and AztraZeneca.

Cleandro Pires Albuquerque has no conflicts of interest.

Wanderley Marques Bernardo has no conflicts of interest.

Percival Degrava Sampaio-Barros received for participation in lectures, boards or scientific events from laboratories Abbvie, Janssen, Novartis, Pfizer and UCB.

Marcelo de Medeiros Pinheiro received financial support for advisory board from Novartis and Janssen; by lectures from Novartis, Janssen, Abbvie.

\section{Author details}

${ }^{1}$ Universidade Federal de Minas Gerais (UFMG), Alameda Álvaro Celso 175, Ambulatório Bias Fortes, $2^{\circ}$ andar, Belo Horizonte, MG 30150-260, Brazil. ${ }^{2}$ Universidade Federal de Pernambuco (UFPE), Recife, PE, Brazil. ${ }^{3}$ Universidade Federal de São Paulo (UNIFESP/ EPM), São Paulo, SP, Brazil. " Universidade Federal do Rio Grande do Sul (UFRGS), Porto Alegre, Brazil. ${ }^{5}$ Universidade de São Paulo (USP), São Paulo, SP, Brazil. ${ }^{6}$ Hospital Estadual Geral de Goiania

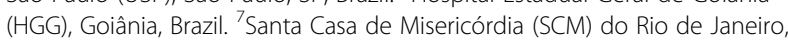
Rio de Janeiro, RJ, Brazil. ${ }^{8}$ Pontifícia Universidade Católica (PUC) de Porto Alegre, Porto Alegre, RS, Brazil. ${ }^{9}$ Pontifícia Universidade Católica (PUC) de Sorocaba, Sorocaba, SP, Brazil. ${ }^{10}$ Santa Casa de Misericórdia (SCM) de São Paulo, São Paulo, SP, Brazil. ${ }^{11}$ Pontifícia Universidade Católica (PUC) de Campinas, Campinas, SP, Brazil. ${ }^{12}$ Hospital Heliópolis, São Paulo, SP, Brazil.

${ }^{13}$ Universidade Estadual de Campinas (UNICAMP), Campinas, SP, Brazil. ${ }^{14}$ Ribeirão Preto, Ribeirão Preto, Brazil. ${ }^{15}$ Hospital do Servidor Público do Estado de São Paulo, São Paulo, SP, Brazil. ${ }^{16}$ Universidade Federal do Rio De Janeiro (UFRJ), Rio de Janeiro, RJ, Brazil. ${ }^{17}$ Universidade Federal do Paraná (UFPR), Curitiba, PR, Brazil. ${ }^{18}$ Universidade de Brasília (UnB), Brasília, DF, Brazil.

Received: 3 July 2020 Accepted: 29 December 2020

Published online: 19 January 2021

\section{References}

1. Rudwaleit M, Landewe R, van der Heijde D, Listing J, Brandt J, Braun J, et al. The development of Assessment of SpondyloArthritis international Society classification criteria for axial spondyloarthritis (part I): classification of paper patients by expert opinion including uncertainty appraisal. Ann Rheum Dis. 2009;68(6):770-6.

2. Rudwaleit M, van der Heijde D, Landewe R, Akkoc N, Brandt J, Chou CT, et al. The Assessment of SpondyloArthritis International Society classification criteria for peripheral spondyloarthritis and for spondyloarthritis in general. Ann Rheum Dis. 2011;70(1):25-31.

3. Rudwaleit M, van der Heijde D, Landewe R, Listing J, Akkoc N, Brandt J, et al. The development of Assessment of SpondyloArthritis international Society classification criteria for axial spondyloarthritis (part II): validation and final selection. Ann Rheum Dis. 2009;68(6):777-83.

4. van der Linden S, Valkenburg HA, Cats A. Evaluation of diagnostic criteria for ankylosing spondylitis. A proposal for modification of the New York criteria. Arthritis Rheum. 1984;27(4):361-8. 
5. Sieper J, van der Heijde D. Review: Nonradiographic axial spondyloarthritis: new definition of an old disease? Arthritis Rheum. 2013;65(3):543-51.

6. van der Heijde D, Ramiro S, Landewe R, Baraliakos X, Van den Bosch F, Sepriano A, et al. 2016 update of the ASAS-EULAR management recommendations for axial spondyloarthritis. Ann Rheum Dis. 2017;76(6): 978-91.

7. Resende GG, Meirelles ES, Marques CDL, Chiereghin A, Lyrio AM, Ximenes AC, et al. The Brazilian Society of Rheumatology guidelines for axial spondyloarthritis - 2019. Adv Rheumatol. 2020;60(1):19.

8. FPB K, der Burg LRA v, Ramiro S, RBM L, Buchbinder R, Falzon L, et al. Nonsteroidal anti-inflammatory drugs (NSAIDs) for axial spondyloarthritis (ankylosing spondylitis and non-radiographic axial spondyloarthritis). Cochrane Database Syst Rev. 2015;17(7):CD010952-CD.

9. Baraliakos X, Kiltz U, Peters S, Appel H, Dybowski F, Igelmann M, et al. Efficiency of treatment with non-steroidal anti-inflammatory drugs according to current recommendations in patients with radiographic and non-radiographic axial spondyloarthritis. Rheumatology (Oxford). 2017;56(1): 95-102.

10. Bhuvanesh M, Balaji C, Saranya C, Ramesh R, Tamilselvam T, Rajeswari S. Serum levels of tumor necrosis factor-alpha and vascular endothelial growth factor as markers of disease activity in patients with axial spondyloarthritis. Indian J Rheumatol. 2018;13(1):9-13.

11. Essers I, Stolwijk C, Boonen A, De Bruin ML, Bazelier MT, de Vries F, et al. Ankylosing spondylitis and risk of ischaemic heart disease: a populationbased cohort study. Ann Rheum Dis. 2016;75(1):203-9.

12. Gaydukova IZ, Gamayunova Cyrillic A cKA, Dorogoykina KD, Rebrov AP. Efficiency of different celecoxib regimens in patients with active axial spondyloarthritis: Results of the 4-week pilot open-label comparative singlecenter study 'AlM'. Ter Arkh. 2017;89(6):78-83.

13. Gaydukova IZ, Rebrov AP. Efficiency and safety of different etoricoxib regimens in patients with axial spondyloarthritis, including ankylosing spondylitis. Ter Arkh. 2015;87(3):77-82.

14. Gratacos J, Moreno Martinez-Losa M, Font P, Montilla C, FernandezEspartero C, Linares LF, et al. Etoricoxib in ankylosing spondylitis: is there a role for active patients refractory to traditional NSAIDs? Clin Exp Rheumatol. 2016;34(1):94-9.

15. Guellec D, Nocturne G, Tatar Z, Pham T, Sellam J, Cantagrel A, et al. Should non-steroidal anti-inflammatory drugs be used continuously in ankylosing spondylitis? Joint Bone Spine. 2014;81(4):308-12.

16. Karateev A, Chernikhova E, Erdes S. AB0735 Upper Gastrointestinal Tract Pathology in Patients with Ankylosing Spondylitis. Ann Rheum Dis. 2015; 74(Suppl 2):1144 LP.

17. Kristensen LE, Jakobsen AK, Askling J, Nilsson F, Jacobsson LTH. Safety of Etoricoxib, Celecoxib, and Nonselective Nonsteroidal Antiinflammatory Drugs in Ankylosing Spondylitis and Other Spondyloarthritis Patients: A Swedish National Population-Based Cohort Study. Arthritis Care Res. 2015; 67(8):1137-49.

18. Maas F, Spoorenberg A, van der Slik BPG, van der Veer E, Brouwer E, Bootsma $\mathrm{H}$, et al. Clinical Risk Factors for the Presence and Development of Vertebral Fractures in Patients With Ankylosing Spondylitis. Arthritis Care Res. 2017;69(5):694-702.

19. Molto A, Granger B, Wendling D, Dougados M, Gossec L. Use of nonsteroidal anti-inflammatory drugs in early axial spondyloarthritis in daily practice: Data from the DESIR cohort. Joint Bone Spine. 2017;84(1):79-82.

20. Regel A, Sepriano A, Baraliakos X, van der Heijde D, Braun J, Landewe R, et al. Efficacy and safety of non-pharmacological and non-biological pharmacological treatment: a systematic literature review informing the 2016 update of the ASAS/EULAR recommendations for the management of axial spondyloarthritis. RMD Open. 2017;3(1):e000397-e.

21. Tam H-W, Yeo K-J, Leong P-Y, Chen C-H, Li Y-C, Ma C-M, et al. Sulfasalazine might reduce risk of cardiovascular diseases in patients with ankylosing spondylitis: A nationwide population-based retrospective cohort study. Int J Rheum Dis. 2017;20(3):363-70.

22. Tang $M, X u e ~ L$, Shen $Y, B o L$, Yang $R$, Wen J, et al. Efficacy of long-term nonsteroidal antiinflammatory drug treatment on magnetic resonance imaging-determined bone marrow oedema in early, active axia spondyloarthritis patients. Clin Rheumatol. 2018;37(1):245-50.

23. Tsai W-C, Ou T-T, Yen J-H, Wu C-C, Tung Y-C. Long-term frequent use of non-steroidal anti-inflammatory drugs might protect patients with ankylosing spondylitis from cardiovascular diseases: a nationwide casecontrol study. PLoS One. 2015;10(5):e0126347-e.
24. Varkas G, Jans L, Cypers H, Van Praet L, Carron P, Elewaut D, et al. Brief Report: Six-Week Treatment of Axial Spondyloarthritis Patients With an Optimal Dose of Nonsteroidal Antiinflammatory Drugs: Early Response to Treatment in Signal Intensity on Magnetic Resonance Imaging of the Sacroiliac Joints. Arthritis Rheumatol (Hoboken, NJ). 2016;68(3):672-8.

25. Wang R, Dasgupta A, Ward MM. Comparative efficacy of non-steroidal antiinflammatory drugs in ankylosing spondylitis: a Bayesian network metaanalysis of clinical trials. Ann Rheum Dis. 2016;75(6):1152-60.

26. Wu L-C, Leong P-Y, Yeo K-J, Li T-Y, Wang Y-H, Chiou J-Y, et al. Celecoxib and sulfasalazine had negative association with coronary artery diseases in patients with ankylosing spondylitis: A nation-wide, population-based casecontrol study. Medicine. 2016;95(36):e4792-e.

27. Couderc M, Pereira B, Molto A, Tiple A, Soubrier M, Dougados M. The Prevalence of Renal Impairment in Patients with Spondyloarthritis: Results from the International ASAS-COMOSPA Study. J Rheumatol. 2018;45(6):795801.

28. Dregan A, Chowienczyk P, Molokhia M. Cardiovascular and type 2 diabetes morbidity and all-cause mortality among diverse chronic inflammatory disorders. Heart (British Cardiac Society). 2017;103(23):1867-73.

29. Fattahi MJ, Jamshidi AR, Mahmoudi M, Vojdanian M, Yekaninejad MS, Jafarnezhad-Ansariha F, et al. Evaluation of the efficacy and safety of beta-dmannuronic acid in patients with ankylosing spondylitis: A 12-week randomized, placebo-controlled, phase I/II clinical trial. Int Immunopharmacol. 2018;54:112-7.

30. Gao G, Lu L, Li Z, Li Y. THU0367 The influences of non-steroidal antiinflammatory drugs on serum VEGF and BMP-2 levels in patients with axial spondyloarthritis. Ann Rheum Dis. 2017;76(Suppl 2):344 LP.

31. Gao G-M, Li Y-M, Zheng X-L, Jiang D-B, Zhang L-L, Xu P-H, et al. The Efficacy of Imrecoxib and Celecoxib in Axial Spondyloarthritis and Their Influence on Serum Dickopff-Related Protein 1 (DKK-1) Levels. Med Sci Monit. 2017;23: 2985-92.

32. Jafarnezhad-Ansariha F, Yekaninejad MS, Jamshidi A-R, Mansouri R, Vojdanian M, Mahmoudi M, et al. The effects of beta-D-mannuronic acid (M2000), as a novel NSAID, on COX1 and COX2 activities and gene expression in ankylosing spondylitis patients and the murine monocyte/ macrophage, J774 cell line. Inflammopharmacology. 2018;26(2):375-84.

33. Bedaiwi M, Thavaneswaran A, Haroon N, Anton A, Inman R. Profiling ankylosing spondylitis patients likely to respond to NSAID treatment; 2014.

34. Zengin O, Kisacık B, Kimyon G, Uyar N, Onat AM. AB0751 Treatment Response in Spondylitis Without Sacroiliitis to Nonsteroidal Antiinflammatory Drugs is More Difficult than Axial Spondyloarthritis. Ann Rheum Dis. 2015;74(Suppl 2):1150.1.

35. Sánchez MD, Montilla-Morales CA, Gómez-Castro S, Hidalgo-Calleja C, Carranco-Medina T, Calero-Paniagua I, et al. AB0705 Nonsteroidal Antiinflammatory Drugs and Bone Mineral Density and Fractures in Patients with Ankylosing Spondylitis. Ann Rheum Dis. 2014;73(Suppl 2):1037 LP.

36. Shukla A, Rai MK, Prasad N, Agarwal V. Short-term non-steroid antiinflammatory drug use in spondyloarthritis patients induces subclinical acute kidney injury: biomarkers study. Nephron. 2017;135(4):277-86.

37. Bedaiwi MK, Sari I, Wallis D, O'Shea FD, Salonen D, Haroon N, et al. Clinical efficacy of celecoxib compared to acetaminophen in chronic nonspecific low back pain: results of a randomized controlled trial. Arthritis Care Res. 2016;68(6):845-52

38. Huang F, Gu J, Liu Y, Zhu P, Zheng Y, Fu J, et al. Efficacy and safety of celecoxib in chinese patients with ankylosing spondylitis: a 6-week randomized, double-blinded study with 6-week open-label extension treatment. Curr Ther Res Clin Exp. 2014;76:126-33.

39. Sieper J, van der Heijde D, Dougados M, Mease PJ, Maksymowych WP, Brown MA, et al. Efficacy and safety of adalimumab in patients with nonradiographic axial spondyloarthritis: results of a randomised placebocontrolled trial (ABILITY-1). Ann Rheum Dis. 2013;72(6):815-22.

40. Walker C, Essex MN, Li C, Park PW. Celecoxib versus diclofenac for the treatment of ankylosing spondylitis: 12-week randomized study in Norwegian patients. J Int Med Res. 2016:44(3):483-95.

41. Balazcs E, Sieper J, Bickham K, Mehta A, Frontera N, Stryszak P, et al. A randomized, clinical trial to assess the relative efficacy and tolerability of two doses of etoricoxib versus naproxen in patients with ankylosing spondylitis. BMC Musculoskelet Disord. 2016;17(1):426.

42. Guyatt G, Oxman AD, Akl EA, Kunz R, Vist G, Brozek J, et al. GRADE guidelines: 1. Introduction-GRADE evidence profiles and summary of findings tables. J Clin Epidemiol. 2011;64(4):383-94. 
43. Guyatt GH, Oxman AD, Kunz R, Falck-Ytter Y, Vist GE, Liberati A, et al. Going from evidence to recommendations. Bmj. 2008;336(7652):1049-51.

44. Barkhuizen A, Steinfeld S, Robbins J, West C, Coombs J, Zwillich S. Celecoxib is efficacious and well tolerated in treating signs and symptoms of ankylosing spondylitis. J Rheumatol. 2006;33(9):1805-12.

45. Dougados M, Behier JM, Jolchine I, Calin A, van der Heijde D, Olivieri I, et al. Efficacy of celecoxib, a cyclooxygenase 2-specific inhibitor, in the treatment of ankylosing spondylitis: a six-week controlled study with comparison against placebo and against a conventional nonsteroidal antiinflammatory drug. Arthritis Rheum. 2001;44(1):180-5.

46. Dougados M, Gueguen A, Nakache JP, Velicitat P, Veys EM, Zeidler H, et al. Ankylosing spondylitis: what is the optimum duration of a clinical study? A one year versus a 6 weeks non-steroidal anti-inflammatory drug trial. Rheumatology (Oxford). 1999;38(3):235-44.

47. Dougados M, Nguyen M, Caporal R, Legeais J, Bouxin-Sauzet A, PellegriGuegnault B, et al. Ximoprofen in ankylosing spondylitis. A double blind placebo controlled dose ranging study. Scand J Rheumatol. 1994;23(5):2438.

48. van der Heijde D, Baraf HSB, Ramos-Remus C, Calin A, Weaver AL, Schiff M, et al. Evaluation of the efficacy of etoricoxib in ankylosing spondylitis: results of a fifty-two-week, randomized, controlled study. Arthritis Rheum. 2005; 52(4):1205-15

49. Sieper J, Klopsch T, Richter M, Kapelle A, Rudwaleit M, Schwank S, et al. Comparison of two different dosages of celecoxib with diclofenac for the treatment of active ankylosing spondylitis: results of a 12-week randomised, double-blind, controlled study. Ann Rheum Dis. 2008;67(3):323-9.

50. Gossec L, van der Heijde D, Melian A, Krupa DA, James MK, Cavanaugh PF, et al. Efficacy of cyclo-oxygenase-2 inhibition by etoricoxib and naproxen on the axial manifestations of ankylosing spondylitis in the presence of peripheral arthritis. Ann Rheum Dis. 2005;64(11):1563-7.

51. Villa Alcazar LF, de Buergo M, Rico Lenza H, Montull Fruitos E. Aceclofenac is as safe and effective as tenoxicam in the treatment of ankylosing spondylitis: a 3 month multicenter comparative trial. Spanish Study Group on Aceclofenac in Ankylosing Spondylitis. J Rheumatol. 1996;23(7):1194-9.

52. Ebner W, Poal Ballarin JM, Boussina I. Meclofenamate sodium in the treatment of ankylosing spondylitis. Report of a European double-blind controlled multicenter study. Arzneimittel-Forschung. 1983;33(4A):660-3.

53. Good A, Mena H. Treatment of ankylosing spondylitis with flurbiprofen and indomethacin. Curr Med Res Opin. 1977;5(1):117-21.

54. Zochling J, Bohl-Buhler MH, Baraliakos X, Feldtkeller E, Braun J. Nonsteroidal anti-inflammatory drug use in ankylosing spondylitis--a population-based survey. Clin Rheumatol. 2006;25(6):794-800.

55. Carbo MJG, Spoorenberg A, Maas F, Brouwer E, Bos R, Bootsma H, et al. Ankylosing spondylitis disease activity score is related to NSAID use, especially in patients treated with TNF-alpha inhibitors. PLoS One. 2018; 13(4):e0196.

56. Zochling J, van der Heijde D, Dougados M, Braun J. Current evidence for the management of ankylosing spondylitis: a systematic literature review for the ASAS/EULAR management recommendations in ankylosing spondylitis. Ann Rheum Dis. 2006;65(4):423-32.

57. Coates LC, Kavanaugh A, Mease PJ, Soriano ER, Laura Acosta-Felquer M, Armstrong AW, et al. Group for Research and Assessment of Psoriasis and Psoriatic Arthritis 2015 Treatment Recommendations for Psoriatic Arthritis. Arthritis Rheum. 2016;68(5):1060-71.

58. Gossec L, Smolen JS, Ramiro S, de Wit M, Cutolo M, Dougados M, et al. European League Against Rheumatism (EULAR) recommendations for the management of psoriatic arthritis with pharmacological therapies: 2015 update. Ann Rheum Dis. 2016;75(3):499-510.

59. Sieper J, Lenaerts J, Wollenhaupt J, Rudwaleit M, Mazurov VI, Myasoutova L, et al. Efficacy and safety of infliximab plus naproxen versus naproxen alone in patients with early, active axial spondyloarthritis: results from the double-blind, placebo-controlled INFAST study, Part 1. Ann Rheum Dis. 2014;73(1):101-7.

60. Sieper J, Lenaerts J, Wollenhaupt J, Rudwaleit M, Mazurov VI, Myasoutova L, et al. Maintenance of biologic-free remission with naproxen or no treatment in patients with early, active axial spondyloarthritis: results from a 6-month, randomised, open-label follow-up study, INFAST Part 2. Ann Rheum Dis. 2014;73(1):108-13.

61. Barkham N, Keen HI, Coates LC, O'Connor P, Hensor E, Fraser AD, et al, Clinical and imaging efficacy of infliximab in HLA-B27-Positive patients with magnetic resonance imaging-determined early sacroiliitis. Arthritis Rheum. 2009;60(4):946-54
62. Ash Z, Barkham N, McGonagle D, Hensor E, Emery P, Marzo-Ortega H. Induction approach to early axial spondyloarthritis: still looking for the window of opportunity. Arthritis Rheum. 2011;63:1285.

63. Baraliakos X, Koenig AS, Jones H, Szumski A, Collier D, Bananis E. Predictors of clinical remission under anti-tumor necrosis factor treatment in patients with ankylosing spondylitis: pooled analysis from large randomized clinical trials. J Rheumatol. 2015;42(8):1418-26.

64. Robinson PC, Brown MA. The window of opportunity: a relevant concept for axial spondyloarthritis. Arthritis Res Ther. 2014;16(3):109.

65. Rudwaleit M, Listing J, Brandt J, Braun J, Sieper J. Prediction of a major clinical response (BASDAI 50) to tumour necrosis factor alpha blockers in ankylosing spondylitis. Ann Rheum Dis. 2004;63(6):665-70.

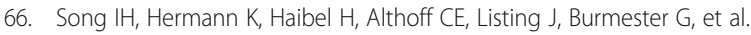
Effects of etanercept versus sulfasalazine in early axial spondyloarthritis on active inflammatory lesions as detected by whole-body MRI (ESTHER): a 48week randomised controlled trial. Ann Rheum Dis. 2011;70(4):590-6.

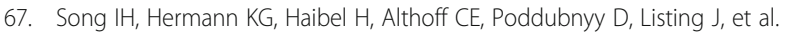
Consistently good clinical response in patients with early axial spondyloarthritis after 3 years of continuous treatment with etanercept: longterm data of the ESTHER trial. J Rheumatol. 2014;41(10):2034-40.

68. Haroon $\mathrm{N}$, Inman RD, Learch $\mathrm{TJ}$, Weisman $\mathrm{MH}$, Lee $\mathrm{M}$, Rahbar $\mathrm{MH}$, et al. The impact of tumor necrosis factor alpha inhibitors on radiographic progression in ankylosing spondylitis. Arthritis Rheum. 2013;65(10):2645-54.

69. Wanders A, Heijde D, Landewe R, Behier JM, Calin A, Olivieri I, et al. Nonsteroidal antiinflammatory drugs reduce radiographic progression in patients with ankylosing spondylitis: a randomized clinical trial. Arthritis Rheum. 2005;52(6):1756-65.

70. Sieper J, Listing J, Poddubnyy D, Song I-H, Hermann K-G, Callhoff J, et al. Effect of continuous versus on-demand treatment of ankylosing spondylitis with diclofenac over 2 years on radiographic progression of the spine: results from a randomised multicentre trial (ENRADAS). Ann Rheum Dis. 2016;75(8):1438-43.

71. Ward MM, Deodhar A, AkI EA, Lui A, Ermann J, Gensler LS, et al. American College of Rheumatology/Spondylitis Association of America/ Spondyloarthritis Research and Treatment Network 2015 recommendations for the treatment of ankylosing spondylitis and nonradiographic axial spondyloarthritis. Arthritis Rheumatol (Hoboken, NJ). 2016;68(2):282-98.

72. Boersma JW. Retardation of ossification of the lumbar vertebral column in ankylosing spondylitis by means of phenylbutazone. Scand J Rheumatol. 1976:5(1):60-4.

73. Poddubnyy D, Rudwaleit M, Haibel H, Listing J, Marker-Hermann E, Zeidler $\mathrm{H}$, et al. Effect of non-steroidal anti-inflammatory drugs on radiographic spinal progression in patients with axial spondyloarthritis: results from the German Spondyloarthritis Inception Cohort. Ann Rheum Dis. 2012;71(10): 1616-22.

74. Kroon F, Landewe R, Dougados M, van der Heijde D. Continuous NSAID use reverts the effects of inflammation on radiographic progression in patients with ankylosing spondylitis. Ann Rheum Dis. 2012;71(10):1623-9.

75. Jeong H, Eun YH, Kim IY, Park EJ, Kim H, Lee J, et al. Effect of tumor necrosis factor alpha inhibitors on spinal radiographic progression in patients with ankylosing spondylitis. Int J Rheum Dis. 2018;21(5):1098-105.

76. Molnar C, Scherer A, Baraliakos X, de Hooge M, Micheroli R, Exer P, et al. TNF blockers inhibit spinal radiographic progression in ankylosing spondylitis by reducing disease activity: results from the Swiss Clinical Quality Management cohort. Ann Rheum Dis. 2018;77(1):63-9.

77. Louie GH, Ward MM. Measurement and treatment of radiographic progression in ankylosing spondylitis: lessons learned from observational studies and clinical trials. Curr Opin Rheumatol. 2014;26(2):145-50.

78. Tannenbaum H, DeCoteau WE, Esdaile JM. A double blind multicenter trial comparing piroxicam and indomethacin in ankylosing spondylitis with long-term follow-up. Curr Therapeut Res - Clin Exp. 1984;36(3):426-35.

79. Astorga G. Double-blind, parallel clinical trial of tenoxicam (Ro 12-0068) versus piroxicam in patients with ankylosing spondylitis. Eur J Rheumatol Inflamm. 1987;9(2):70-3.

80. Caldwell JR, Altman RD, Burch FX, Calin A. Treatment of ankylosing spondylitis with oxaprozin: a comparison with indomethacin. Semin Arthritis Rheum. 1986;15(3, Supplement 2):95-100.

81. Calin A, Britton M. Sulindac in ankylosing spondylitis. Double-blind evaluation of sulindac and indomethacin. JAMA. 1979;242(17):1885-6.

82. Heinrichs KK. Treatment of spondylitis ankylosans: controlled comparative study with tiaprofenic acid and diclofenac. Med Klin. 1985;80(21):597-601. 
83. Khan MA. Diclofenac in the treatment of ankylosing spondylitis: review of worldwide clinical experience and report of a double-blind comparison with indomethacin. Semin Arthritis Rheum. 1985;15(2 Suppl 1):80-4.

84. Lomen $\mathrm{PL}$, Turner LF, Lamborn KR, Brinn EL. Flurbiprofen in the treatment of ankylosing spondylitis. a comparison with indomethacin. Am J Med. 1986; $80(3 \mathrm{~A}): 127-32$

85. Lomen PL, Turner LF, Lamborn KR, Brinn EL, Sattler LP. Flurbiprofen in the treatment of ankylosing spondylitis. A comparison with phenylbutazone. Am J Med. 1986;80(3A):120-6.

86. Batlle-Gualda E, Figueroa M, Ivorra J, Raber A. The efficacy and tolerability of aceclofenac in the treatment of patients with ankylosing spondylitis: a multicenter controlled clinical trial. Aceclofenac Indomethacin Study Group. J Rheumatol. 1996;23(7):1200-6.

87. Mena HR, Good AE. Management of ankylosing spondylitis with flurbiprofen or indomethacin. South Med J. 1977;70(8):945-7.

88. Nissila M, Kajander A. Proquazone (Biarison) and indomethacin (Indocid) in the treatment of ankylosing spondylitis. Two comparative, clinical, doubleblind studies. Scand J Rheumatol Suppl. 1978;7(21):36-9.

89. Palferman TG, Webley M. A comparative study of nabumetone and indomethacin in ankylosing spondylitis. Eur J Rheumatol Inflamm. 1991; 11(2):23-9.

90. Pasero G, Ruju G, Marcolongo R, Senesi M, Seni U, Mannoni A, Mannoni A, et al. Aceclofenac versus naproxen in the treatment of ankylosing spondylitis: A double-blind, controlled study. Curr Therapeut Res - Clin Exp. 1994;55(7):833-42.

91. Rejholec V, Vapaatalo H, Tokola O, Gothoni G. Tolfenamic acid in ankylosing spondylarthritis: a double-blind comparison to indomethacin. Scand J Rheumatol Suppl. 1980;36:1-7.

92. Franssen MJ, Gribnau FW, van de Putte LB. A comparison of diflunisal and phenylbutazone in the treatment of ankylosing spondylitis. Clin Rheumatol. 1986;5(2):210-20.

93. Jessop JD. Double-blind study of ketoprofen and phenylbutazone in ankylosing spondylitis. Rheumatol Rehabil. 1976;15(Suppl 5):37-42.

94. Schwarzer AC, Cohen M, Arnold MH, Kelly D, McNaught P, Brooks PM. Tenoxicam compared with diclofenac in patients with ankylosing spondylitis. Curr Med Res Opin. 1990;11(10):648-53.

95. Simpson MR, Simpson NR, Scott BO, Beatty DC. A controlled study of flufenamic acid in ankylosing spondylitis. A preliminary report. Ann Phys Med. 1966:8(Suppl 1):126-8.

96. Myklebust G. Comparison of naproxen and piroxicam in rheumatoid arthritis and Bechterew's syndrome. A double-blind parallel multicenter study. Tidsskr Nor Laegeforen. 1986;106(17-18):1485-7.

97. Nahir AM, Scharf Y. A comparative study of diclofenac and sulindac in ankylosing spondylitis. Rheumatol Rehabil. 1980;19(3):193-8.

98. Santo JE, Queiroz MV. Oxaprozin versus diclofenac sodium in the treatment of ankylosing spondylitis. J Int Med Res. 1988;16(2):150-6.

99. Ansell BM. A comparative study of Butacote and naproxen in ankylosing spondylitis. J Int Med Res. 1977;5(Suppl 2):95.

100. Coxib, traditional NTC, Bhala N, Emberson J, Merhi A, Abramson S, et al. Vascular and upper gastrointestinal effects of non-steroidal antiinflammatory drugs: meta-analyses of individual participant data from randomised trials. Lancet. 2013;382(9894):769-79.

101. Kearney PM, Baigent C, Godwin J, Halls H, Emberson JR, Patrono C. Do selective cyclo-oxygenase-2 inhibitors and traditional non-steroidal antiinflammatory drugs increase the risk of atherothrombosis? Meta-analysis of randomised trials. Bmj. 2006;332(7553):1302-8.

102. Lanas A, Boers M, Nuevo J. Gastrointestinal events in at-risk patients starting non-steroidal anti-inflammatory drugs (NSAIDs) for rheumatic diseases: the EVIDENCE study of European routine practice. Ann Rheum Dis. 2015;74(4): 675-81.

103. Poddubnyy D, van der Heijde D. Therapeutic controversies in spondyloarthritis: nonsteroidal anti-inflammatory drugs. Rheum Dis Clin North Am. 2012;38(3):601-11.

104. Bakland G, Gran JT, Nossent JC. Increased mortality in ankylosing spondylitis is related to disease activity. Ann Rheum Dis. 2011;70(11):1921-5.

105. Haroon NN, Paterson JM, Li P, Inman RD, Haroon N. Patients with ankylosing spondylitis have increased cardiovascular and cerebrovascular mortality: a population-based study. Ann Intern Med. 2015;163(6):409-16.

106. Lehtinen K. Mortality and causes of death in 398 patients admitted to hospital with ankylosing spondylitis. Ann Rheum Dis. 1993:52(3):174-6.
107. Liew JW, Ramiro S, Gensler LS. Cardiovascular morbidity and mortality in ankylosing spondylitis and psoriatic arthritis. Best Pract Res Clin Rheumatol. 2018;32(3):369-89.

108. Fosbol EL, Gislason GH, Jacobsen S, Folke F, Hansen ML, Schramm TK, et al. Risk of myocardial infarction and death associated with the use of nonsteroidal anti-inflammatory drugs (NSAIDs) among healthy individuals: a nationwide cohort study. Clin Pharmacol Ther. 2009;85(2):190-7.

109. Trelle S, Reichenbach S, Wandel S, Hildebrand P, Tschannen B, Villiger PM, et al. Cardiovascular safety of non-steroidal anti-inflammatory drugs: network meta-analysis. Bmj. 2011;342:c7086.

110. Gislason GH, Jacobsen S, Rasmussen JN, Rasmussen S, Buch P, Friberg J, et al. Risk of death or reinfarction associated with the use of selective cyclooxygenase-2 inhibitors and nonselective nonsteroidal antiinflammatory drugs after acute myocardial infarction. Circulation. 2006;113(25):2906-13.

111. Nussmeier NA, Whelton AA, Brown MT, Langford RM, Hoeft A, Parlow JL, et al. Complications of the COX-2 inhibitors parecoxib and valdecoxib after cardiac surgery. N Engl J Med. 2005;352(11):1081-91.

112. Dubreuil M, Louie-Gao Q, Peloquin CE, Choi HK, Zhang Y, Neogi T. Risk of myocardial infarction with use of selected non-steroidal anti-inflammatory drugs in patients with spondyloarthritis and osteoarthritis. Ann Rheum Dis. 2018;77(8):1137-42.

113. Winkelmayer WC, Waikar SS, Mogun H, Solomon DH. Nonselective and cyclooxygenase-2-selective NSAIDs and acute kidney injury. Am J Med. 2008;121(12):1092-8.

114. Ungprasert P, Cheungpasitporn W, Crowson CS, Matteson EL. Individual non-steroidal anti-inflammatory drugs and risk of acute kidney injury: A systematic review and meta-analysis of observational studies. Eur J Intern Med. 2015;26(4):285-91.

115. Gooch K, Culleton BF, Manns BJ, Zhang J, Alfonso H, Tonelli M, et al. NSAID use and progression of chronic kidney disease. Am J Med. 2007;120(3):280 e1-7.

116. Cao YL, Tian ZG, Wang F, Li WG, Cheng DY, Yang YF, et al. Characteristics and clinical outcome of nonsteroidal anti-inflammatory drug-induced acute hepato-nephrotoxicity among Chinese patients. World J Gastroenterol. 2014; 20(38):13956-65.

\section{Publisher's Note}

Springer Nature remains neutral with regard to jurisdictional claims in published maps and institutional affiliations.

Ready to submit your research? Choose BMC and benefit from:

- fast, convenient online submission

- thorough peer review by experienced researchers in your field

- rapid publication on acceptance

- support for research data, including large and complex data types

- gold Open Access which fosters wider collaboration and increased citations

- maximum visibility for your research: over $100 \mathrm{M}$ website views per year

At $\mathrm{BMC}$, research is always in progress.

Learn more biomedcentral.com/submissions 